San Jose State University

SJSU ScholarWorks

Master's Theses

Master's Theses and Graduate Research

1998

\title{
Effect of cryotherapy on athletes' performance on three functional tests of agility
}

Paul A. Starks

San Jose State University

Follow this and additional works at: https://scholarworks.sjsu.edu/etd_theses

\section{Recommended Citation}

Starks, Paul A., "Effect of cryotherapy on athletes' performance on three functional tests of agility" (1998). Master's Theses. 1774.

DOI: https://doi.org/10.31979/etd.c58x-99ms

https://scholarworks.sjsu.edu/etd_theses/1774

This Thesis is brought to you for free and open access by the Master's Theses and Graduate Research at SJSU ScholarWorks. It has been accepted for inclusion in Master's Theses by an authorized administrator of SJSU ScholarWorks. For more information, please contact scholarworks@sjsu.edu. 


\section{INFORMATION TO USERS}

This manuscript has been reproduced from the microfilm master. UMI films the text directly from the original or copy submitted. Thus, some thesis and dissertation copies are in typewriter face, while others may be from any type of computer printer.

The quality of this reproduction is dependent upon the quality of the copy submitted. Broken or indistinct print, colored or poor quality illustrations and photographs, print bleedthrough, substandard margins, and improper alignment can adversely affect reproduction.

In the unlikely event that the author did not send UMI a complete manuscript and there are missing pages, these will be noted. Also, if unauthorized copyright material had to be removed, a note will indicate the deletion.

Oversize materials (e.g., maps, drawings, charts) are reproduced by sectioning the original, beginning at the upper left-hand comer and continuing from left to right in equal sections with small overlaps. Each original is also photographed in one exposure and is included in reduced form at the back of the book.

Photographs included in the original manuscript have been reproduced xerographically in this copy. Higher quality 6" $\times 9$ " black and white photographic prints are available for any photographs or illustrations appearing in this copy for an additional charge. Contact UMI directly to order.

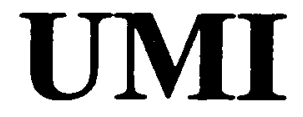

A Bell \& Howell Information Company 300 North Zeeb Road, Ann Arbor MI 48106-1346 USA 



\title{
EFFECT OF CRYOTHERAPY ON ATHLETES' PERFORMANCE ON THREE FUNCTIONAL TESTS OF AGILITY
}

\author{
A Thesis \\ Presented to \\ The Faculty of the Department of Human Performance \\ San Jose State University
}

\author{
In Partial Fulfillment \\ of the Requirements for the Degree \\ Master of Science
}

by

Paul A. Starks

November 1998 
UMI Number: 1392839

UMI Microform 1392839

Copyright 1999, by UMI Company. All rights reserved.

This microform edition is protected against unauthorized copying under Title 17, United States Code.

\author{
UMI \\ 300 North Zeeb Road \\ Ann Arbor, MI 48103
}


(c) 1998

Paul A. Starks

ALL RIGHTS RESERVED 
APPROVED FOR THE DEPARTMENT OF HUMAN PERFORMANCE

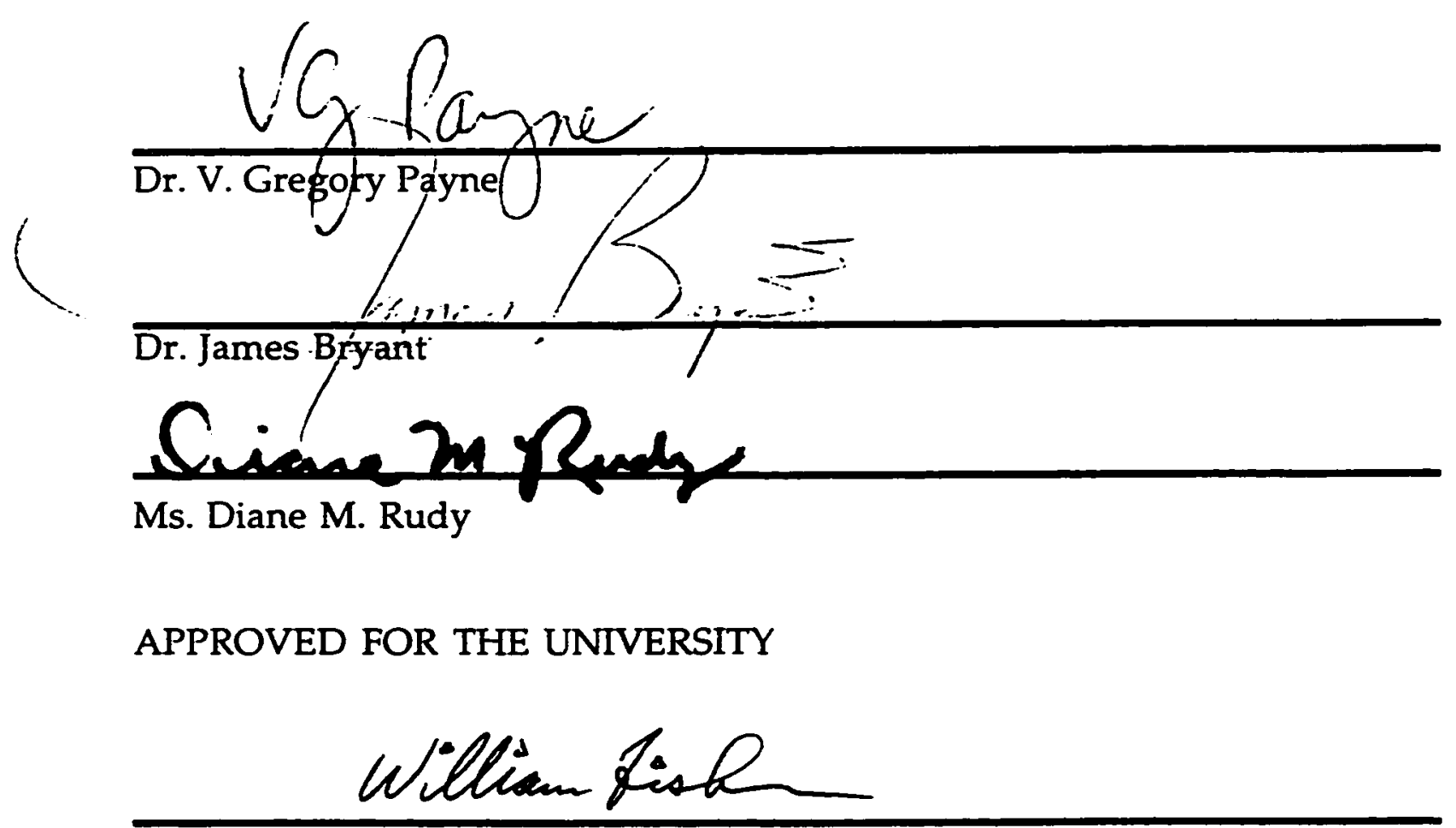




\section{ABSTRACT \\ THE EFFECTS OF CRYOTHERAPY ON ATHLETES' PERFORMANCE ON THREE FUNCTIONAL TEST OF AGILITY}

The practice of pre-icing has been commonly used for its analgesic effect prior to athletic activity and therapeutic exercise with no clear understanding of how it may affect an athlete's level of functional agility. Determining whether this modality affects an athlete's ability to perform agility-type maneuvers required in their sport is difficult. Most prior studies in this area have provided valuable laboratory data, but few have investigated its effect on functional agility on the playing field. Twenty-two non-injured collegiate athletes, 10 males and 12 females, served as treatment (20-minute ice pack application) or control subjects in a pretest - posttest design. All subjects performed the following three functional agility exercises: shuttle run, carioca maneuver, and a figure eight test. Results from six independent t-tests indicated there was no significant difference in functional agility times between the ice treatment and control sessions. The analgesic effect of a 20minute ice pack application to the lateral ankle does not affect functional agility in athletes. 


\section{Table of Contents}

List of Tables vii

Chapter 1 - Introduction 1

Statement of Problem 3

Statement of the Purpose 4

Null Hypothesis $\quad 4$

Delimitations $\quad 5$

$\begin{array}{ll}\text { Limitations } & 6\end{array}$

Definition of Terms $\quad 6$

$\begin{array}{ll}\text { Operational Definition } & 7\end{array}$

Chapter 2 - Review of Literature 8

$\begin{array}{ll}\text { Physiology of Cryotherapy } & 9\end{array}$

Effects of Cryotherapy on Joint Tissue 18

Joint Proprioception following Cryotherapy 23

Neurophysiology of Joint Proprioception 25

Effects of Joint Injury on Proprioception 28

Functional Testing for the Lower Extremity 39

Summary and Proposal 44

Chapter 3 - Methods and Procedures 45

$\begin{array}{ll}\text { Subjects } & 45\end{array}$

$\begin{array}{ll}\text { Instruments } & 47\end{array}$

$\begin{array}{ll}\text { Research Design } & 48\end{array}$

$\begin{array}{ll}\text { Statistical Analysis } & 51\end{array}$ 
Chapter 4 - Results 53

Subjects and Testing Results 54

Subjective Responses $\quad 58$

Chapter 5 - Discussion $\quad 60$

$\begin{array}{ll}\text { Summary } & 61\end{array}$

$\begin{array}{ll}\text { Discussion } & 62\end{array}$

Practical Application $\quad 66$

$\begin{array}{ll}\text { Conclusions } & 67\end{array}$

$\begin{array}{ll}\text { Recommendations } & 68\end{array}$

$\begin{array}{ll}\text { References } & 69\end{array}$

$\begin{array}{ll}\text { Appendices } & 77\end{array}$

Appendix A - Human Subjects Approval Form $\quad 79$

Appendix B - Sign-up Sheet for Volunteer Subjects $\quad 81$

Appendix C - Subject Consent Form 83

Appendix D - Questionnaire of Volunteer Subjects $\quad 85$

Appendix E - Testing Sequence Board 87

Appendix F - Functional Agility Tests Data Sheet 89

Appendix G - Functional Agility Tests 91

Appendix H - Subject Roster Form 94

Appendix I - Agility Testing Site 96 


\section{List of Tables}

Tables

1 Descriptive Data for Subjects 55

2 Agility Scores for Female Subjects 56

3 Agility Scores for Male Subjects 56

$4 \quad$ Mean Differences for Female Subjects 57

$5 \quad$ Mean Differences for Male Subjects $\quad 57$ 


\section{Chapter 1}

\section{Introduction}

Cryotherapy, or the application of cold, is a therapeutic modality widely used by athletic trainers to treat acute, soft tissue injuries (Bocobo, Fast, Kingery \& Kaplan, 1991; Cornwall, 1994; Kowal, 1983; Merrick, Knight, Ingersoll \& Potteiger, 1993). It has become one of the most common treatments in sports medicine (Merrick et al., 1993), yet there is much confusion regarding its use in treating acute and chronic injuries (McLean, 1989). Various forms of cryotherapy are used prior to therapeutic exercises or athletic performance (Merrick et al., 1993) to reduce pain (Ingersoll, Knight \& Merrick, 1992; Taylor, Waring \& Brashear, 1995) and allow more vigorous pain-free exercise (McLean, 1989). Although this practice of pre-cooling prior to exercise or competition has been administered by athletic trainers, whether this influences the functional performance of athletes is uncertain (Evans, Ingersoll, Knight \& Worrel, 1995). Currently, this area of investigation has proponents (Brooks, Ingersoll \& Knight, 1995; Starkey, 1976) and opponents (Barnes \& Larson, 1985; Coppin, Livingstone \& Kuehn, 1978) to cryotherapy before exercise or performance. Some believe that pre-icing before a skilled performance may distort the ability to acknowledge sensory stimuli (LaRiviere, 1994) which could predispose an athlete to injury. The specific effects on sensory perception are not clear (Ingersoll et al., 1992), and athletic trainers have relied on laboratory results from isokinetic cryotherapy studies (Ruiz, Myrer, Durrant \& Fellingham, 1993) to determine when an athlete was 
ready to exercise or return to competition following cryotherapy. Most of the previous studies (Cornwall, 1994; Howard, Kraemer, Stanley, Armstrong \& Maresh, 1994) investigated the effects of pre-icing muscle tissue, however, whether the same response occurs when cooling a joint is still uncertain (Evans et al., 1995). Ankle sprains are common during an event or competition, and immediately treated with ice to control swelling and reduce pain (Bugai, 1975; LaRiviere, 1994). For many athletic trainers, the current literature is not clear on whether an athlete can safely return to play immediately following cryotherapy. Some researchers (Cross, Wilson \& Perrin, 1996; Narodowy et al., 1996) have claimed that the effects of cryotherapy on joint proprioception and kinesthetic awareness could put the athlete at risk for further injury, while others (Evans et al., 1995; Thieme, Ingersoll, Knight \& Ozmun, 1996) opposed this view. Most of the current literature investigated cryotherapy's effect on muscle strength (Barnes \& Larson, 1985; Coppin et al., 1978), balance tests using laboratory equipment (Gandevia \& MCCloskey, 1976; Glencross \& Thornton, 1981), and the effects of ice water immersion on muscles (Coppin et al., 1978) and joints (Evans et al., 1995; Thieme et al., 1996). Although findings from the literature conveyed valuable information regarding the effects of cryotherapy, a majority of these studies were conducted in a laboratory-type setting with no clear measurement as to how functional performance could be affected. No investigations of actual physical performance following cold application have been conducted. Athletic trainers today need clarity regarding the effects of 
cryotherapy on athletes prior to an event or competition. Relying on the laboratory research from the literature, subjective information from the athlete, and an understanding of the physiological effects of cold applied to human tissue is not adequate for determining the effects of cryotherapy on performance.

Statement of the Problem

Following on-field evaluation and cryotherapy for minor injuries in practice or games, athletes are sometimes cleared for return to play by athletic trainers (Ruiz et al., 1993). In the rehabilitation setting, similar injured joints are pre-iced (LaRiviere, 1994) to tolerate active and passive therapeutic exercise with minimal pain and discomfort. In both cases, cryotherapy is practiced by the athletic trainer without pertinent knowledge of the physiological effects (Bugaj, 1975). Yet, how cryotherapy, prior to functional agility exercises, may impair performance and possibly cause injury is still unclear. Athletic trainers today find themselves in the position of having to determine whether the effects of cryotherapy, prior to therapeutic exercise or competition, will affect proprioception, functional agility and ultimately, performance. 


\section{Statement of Purpose}

The purpose of this study was to determine how three functional agility tests were affected immediately following a 20-minute ice pack application to the non-dominant uninjured ankle.

\section{Null Hypothesis}

1. There will be no overall mean change in the shuttle run, functional agility, times between the control and treatment male subjects (pretest posttest) following cryotherapy treatment.

2. There wil be no overall mean change in the carioca maneuver, functional agility, times between the control and treatment male subjects (pretest - posttest) following cryotherapy treatment.

3. There will be no overall mean change in the figure eight, functional agility, times between the control and treatment male subjects following cryotherapy treatment.

4. There will be no overall mean change in the shuttle run, functional agility, times between the control and treatment female subjects (pretest posttest) following cryotherapy treatment.

5. There will be no overall mean change in the carioca manuever, functional agility, times between the control and treatment female subjects (pretest - posttest) following cryotherapy treatment.

6. There will be no overall mean change in the figure eight, functional agility, times between the control and treatment female subjects (pretest posttest) following cryotherapy treatment. 
7. There will be no subjective complaints of ankle discomfort, or obvious loss of balance when male and female treatment subjects perform the three functional agility tests.

\section{Delimitations}

This study was delimited to the following parameters:

1. Subjects were volunteer intercollegiate football or soccer athletes enrolled as community college students.

2. Subjects had no history of injury to the lower extremity, and no balance related conditions.

3. A single-limb hop for distance test (Keskula, Duncan, Davis, \& Finley, 1996) served as the test to determine each subject's non-dominant leg.

4. The cryotherapy treatment was administered on a simulated sideline of a playing field, and only the non-dominant uninjured ankle received treatment.

5. The cryotherapy treatment used was an ice pack applied with an elastic wrap, and administered with the subject supine on a treatment table with the non-injured (treatment) leg elevated.

6. The three functional agility tests were conducted on a grass field to simulate the actual playing surface for soccer and football athletes.

7. The functional agility tests were: a figure eight test (Keskula et al., 1996); a forward shuttle run (Cross et al., 1996; Evans et al., 1995); and a carioca maneuver (Evans et al., 1995). 


\section{Limitations}

This study was limited by the following factors:

1. Subject participation was limited to intercollegiate soccer and football athletes enrolled in a community college.

2. Results of the functional agility test scores were limited to the degree of motivation for each subject tested.

3. The investigator had no control over the activities of the subjects outside of the study.

4. Interpretation of experimental results and data may have been affected by investigator bias.

\section{Definition of Terms}

The following terms were used in this study, and the definition of these terms were presented here for clarification.

Analgesia. "Absence of the sense of pain." (Bugaj, 1975, p. 14)

Athletic Training. "An allied health profession responsible for the prevention, emergency care, first aid, evaluation, and rehabilitation of athletic injuries." (Fandel, 1994, p. 4)

Certified Athletic Trainer. A board-certified allied health professional who provides health care to organized athletic populations and is certified by the National Athletic Trainers' Association." (Fandel, 1994, p. 5)

Cryotherapy. "The local application of cold to diminish the inflammatory reaction to trauma, to reduce edema, hematoma formation and pain." (Meeusen and Lievens, 1986, p. 399) 
Eunctional Agility. "The ability to perform skilled and coordinated movements over a specific time, and is a measurable indicator of functional performance, and essential to optimal athletic performance."

(Evans et. al, 1995, p. 231)

Kinesthesia. "The ability to discriminate joint position, relative weight of body parts, and joint movement including direction, amplitude, and speed." (Newton, 1982, p. 27)

Proprioception. "A specialized variation of the sensory modality of touch that encompasses the sensation of joint movement (kinesthesia) and joint position" (Lephart, Pincivero, Giraldo, \& Fu, 1997, p. 130) Operational Definitions

The following operational terms are defined specific to this study: Cooling. Decreasing the temperature of a body part by the application of cold.

Pre-icing. The application of cold prior to exercise or performance. 


\section{Chapter 2}

\section{Review of the Literature}

The purpose of this study was to determine whether functional agility, was affected by pre-icing to non-injured ankles. The relevant findings from the laboratory research in this review of literature served as a foundation for examining its effects being tested on an outdoor playing field.

The following literature review was an investigation of how cryotherapy for athletic injuries was currently being utilized prior to competition or therapeutic exercise. Certified athletic trainers across the country, for years, have relied on research regarding the implementation of cryotherapy following injury, and could benefit from pertinent information regarding cryotherapy to an injured joint prior to performance. During athletic competition or performance it is often the certified athletic trainer that assesses and treats injuries. Immediately following assessment and cold treatment for minor joint sprains, certified athletic trainers must determine whether the injured athlete can return to play. Unlike standard protocols for cold therapy following injury or competition, the current available literature was unclear regarding pre-icing protocols and its effect on performance or possible re-injury.

In the literature review, the following sections were presented to convey current information regarding the use of cryotherapy and its effect on functional agility: (1) physiology of cryotherapy, (2) effects of cryotherapy on joint tissue, (3) joint proprioception following cryotherapy, 
(4) neurophysiology of joint proprioception, (5) effects of joint injury on proprioception, (6) functional testing for the lower extremity, and (7) a summary and proposal for further investigation of testing the effects of preicing on functional performance.

\section{Physiology of Cryotherapy}

In 1976, Starkey published local, state, and national statistics regarding participation time loss in football athletes who sustained ankle injuries. According to Starkey (1976), the modality of choice (cold or heat) for athletic trainers had a great impact on healing time and return to play. The purpose of his 1976 study was to investigate a modality that combined cold, exercise and massage to assist in venous return. Thirteen subjects from the Miami Dolphins' Professional Football Club and a local high school football team participated in the study, and all had sustained inversion ankle sprains. An air splint-type boot was donned by each subject with a 15 second alternating inflation and deflation of one to two pounds of pressure. Average treatment time with the leg elevated was 30 minutes, and the boot temperature was approximately 37 degrees Fahrenheit. In comparison to the normal ice, compression and elevation treatment typically used, the author found an average two day reduction in time loss using the air splint massage unit. Analgesia from the cold and the alternating compression allowed the athletic trainers to initiate early range of motion exercises to facilitate healing.

Merrick et al. (1993), almost twenty years after Starkey's 1976 study, continued a similar search to determine how compression affected cooling. 
According to Merrick et al. (1993), research studies investigating the combination of ice and compression were rarely conducted. Eleven college students (average age of 23) participated in four treatment conditions: ice only, compression only, ice and compression, and no treatment (control). Measurements of the thigh's skin and muscle tissue, and air temperature were made with surface and implantable thermocouples interfaced with an electronic thermometer. Temperature was measured every 30 seconds, and the treatment sessions were divided into three subsections: five minute preapplication, 30 minute application and a 20 minute post-application. A manometer was also used to measure consistency with the pressure (42 to 48 $\mathrm{mm} \mathrm{Hg}$ ) in which the elastic wraps were applied. Merrick et al. found significantly cooler temperatures at all depths with the ice and compression condition. These temperatures were greater than the ice alone temperatures, and the 20-minute post-application temperatures had not returned to preapplication temperatures. Merrick et al. concluded ice with compression was more effective than ice alone in treating injured tissue.

Bugaj (1975) conveyed the importance of early motion for people with painful injuries, and identified ice-massage as a form of analgesia to relieve the pain and allow motion. He, however, acknowledged that little was known about the physiological effects of cold.

"Cold has been prescribed therapeutically for centuries without pertinent knowledge of the physiological effects, but enough treatments have produced beneficial results to justify continued use of cold therapeutic procedures." (Bugaj, 1975, p. 11) 
The purpose of Bugaj's 1975 study was to obtain objective data regarding the cooling rate of ice massage and the rate of rewarming following treatment. Sixteen male and female subjects (ages 16 to 27 years), with no history of injury, participated in four testing sessions in which two of the sessions served as controls. A telethermometer was used with thermistor probes attached to the left and right gastrocnemius bellies, under the subject's tongue, at room air, and at the base of the hot or cold modality being used. Temperatures were monitored at one-minute intervals as an ice cup was massaged in a ten-centimeter circular pattern on the right gastrocnemius muscle for 10 minutes. A standardized pinpricking device was used every 30seconds to determine the degree of analgesia, and then used in posttreatment for determining when rewarming eliminated analgesia. Bugaj found the mean analgesic effect for the gastrocnemius occurred at one-minute, 45seconds, and concluded at two-minutes and 57 seconds post-ice massage. The average duration for analgesia was 11 minutes. The 10 minute ice massage treatment had no significant effect on the contralateral gastrocnemius of these subjects. Bugaj concluded this brief time period of analgesia was sufficient for initiating early motion in a more pain-tolerable manner.

Baker \& Bell (1991) used impedance plethysmography to examine how ice massage and ice pack treatments to the gastrocnemius affected blood flow. These authors also examined blood flow during and following heat pack and ultrasound with or without heat or ice, but the information here conveys how blood flow was affected by cold. 
According to Baker \& Bell (1991), the mechanism in which cold controlled acute swelling was still unclear. So, they studied nine male subjects (average age 21 years) by placing electrodes on the gastrocnemius along with a four by six inch foam rubber cut-out to serve as the treatment perimeter. Blood flow for the $\mathbf{2 0}$ minute ice pack and ice massage sessions were monitored every minute and up to 45 minutes following treatment. According to the authors, blood flow during the ice pack treatment and the ice massage treatment was greater than results from the control. However, blood flow was lower during the first five minutes of the ice pack treatment.

Taber, Contryman, Fahrenbruch, LaCount and Cornwall (1992) used an impedance plethysmograph, along with venous occlusion, to examine how cold affected blood volume in nontraumatized ankles. Thirteen male and female subjects (ages 18 to 30 years) with no previous ankle or foot pathology underwent two treatment conditions on two different days: a control condition followed by a randomly selected room temperature gel pack (RTGP) application or cold gel pack application (CGP), and the control condition followed by the experimental condition remaining (RTGP or CGP). Four electrodes were placed around the perimeter of the lateral malleolus while subjects were prone. Blood pressure, resting heart rate and room temperature were recorded. A blood pressure cuff was applied to the distal femur and inflated to each subject's resting diastolic blood pressure for 30 seconds. The CGP (10 to 20 degrees Fahrenheit) and RTGP were wrapped in pillowcases and applied to the lateral malleolus region for 20 minutes, while 
plethysmographic readings were recorded every three minutes. Average skin temperature reduction for the CGP was 17.7 degrees Celsius, and the 20 minute treatment time caused an immediate and sustained reduction in local blood volume with the venous occlusion. Taber et al. (1992) found the increase with the CGP application was 60 percent less than that compared to the resting condition. The authors concluded this was due to the cold temperature and the weight of the CGP. No signs were found which indicated reactive vasodilation had occurred.

Taber and Cornwall joined with Weston and Casagranda in a 1994 study to apply the framework of their previous research to traumatized ankles. These authors used the same impedance plethysmograph, and in a similar design they attempted to measure the effects of a cold gel pack (CGP) on the blood volume for acute, ankle inversion sprains. For this study, fifteen male and female subjects (ages 18-46 years) were examined under a 20 minute ice pack treatment and rest condition (control). The subjects were prone on a table with electrodes placed around the lateral malleolus region, and blood pressure cuff was installed proximal to the knee for venous occlusion. Similar to the previous study, resting values were obtained (blood pressure, heart rate and room temperature), and then a 20 degree Fahrenheit ice pack in a pillowcase was applied to the ankle. Ten measurement points were recorded, while the thigh cuff was inflated and maintained $20 \mathrm{~mm} \mathrm{Hg}$ below each subject's resting diastolic blood pressure. The investigators inflated the cuff every two minutes for 30 seconds to obtain the 10 volume 
measurements during the $\mathbf{2 0}$ minute control. Results of this study indicated the increase in blood volume for the treated limb was 50 percent less than for the resting condition. Weston et al. (1994) concluded the reduced increase in volume was due to cold causing reflex vasoconstriction and the weight of the ice pack which served as compression to onset of swelling.

The purpose of a 1979 study by Knight and Londeree was to examine and compare ankle blood flow during therapeutic applications of heat, cold, and exercise. The authors acknowledged that cryokinetics had yielded clinical success, but prior literature lacked scientific support for the phenomenon. Twelve uninjured college students (males) were tested on six different occasions for the following treatments: 1) heat packs, 2) cold packs, 3) control 4) heat-exercise, 5) cold-exercise, 6) control-exercise. For the exercise treatments, subjects interspersed treadmill walking ( 5 three minute bouts at 3.5 miles per hour) with either heat, cold or no (control) treatments for a 45 minute period. For the non-exercise treatments, heat, ice or no treatment (control) was administered for 25 minutes, followed by the remaining 20 minutes of no treatment. Occlusion of the blood flow to the lower leg was provided above the knee with a blood pressure cuff, similar to the protocols of Weston et al. (1994) and Taber et al. (1992). The investigators measured blood flow in the ankle region pre and post-exercise, and devised a method for estimating blood flow during exercise. Results indicated a decrease in blood flow during cold treatment, and this remained at a decreased level of flow for the $\mathbf{2 0}$ minutes of recording data. However, the authors found cold- 
exercise produced greater total blood flow than the heat treatments. No reflex vasodilation was observed, and the authors concluded this form of cryokinetics was useful in initiating active movement in a painful joint.

Hocutt, Jaffe, Rylander and Beebe (1982) conducted a cryotherapy study to assess recovery from ankle sprains. Although athletic trainers had been using cryotherapy to treat acute injuries for years, Hocutt et al. (1982) indicated no controlled studies on its comparison with heat therapy, for a rapid recovery, could be found in a Medline search, 1966 to 1981 . Thirtyseven men and women (ages 15 to 46 , and one 8-year old) with prior ankle sprains (Grades three and four in severity) were treated by either cryotherapy or heat therapy (15 minutes, one to three times per day) for a minimum period of three days. Cryotherapy treatments consisted of an ice whirlpool or ice pack, while the heat therapy was a warm soak or heating pad. The following three treatments were also applied: 1) treatment and ace wrapping applied within an hour post-injury, 2) same treatment, but commenced one to 36 hours post-injury, 3) no treatment or ace wrapping for 36 hours postinjury. The investigators concluded testing by having each of the subjects indicate the time (number of days) required to return to walking, running, jumping and climbing stairs pain-free. Results indicated it took an average of six days for the grade three sprains abiding by the number one treatment method to run and jump, but 11 days for the second treatment method. Subjects using heat therapy for grade three sprains required two weeks before returning to running and jumping pain-free. The grade four ankle sprains 
conveyed similar results as treatment within one hour post-injury required approximately two weeks, while those beginning treatment at least 36 hours post-injury required a month to return to running and jumping. Hocutt et al. concluded that immediate cryotherapy cleared injury debris, prevented muscle atrophy and fewer adhesions, enabling those with ankle sprains to return sooner (average 15 days) than those treated with heat therapy or delayed cryotherapy.

According to Mancuso and Knight (1992), many of the previous studies investigating temperature changes with cryotherapy had been conducted on sedentary subjects. Understanding that most athletic injuries occurred during exercise, Mancuso and Knight (1992) examined how prior exercise affected ankle skin temperature during and following a 30-minute ice pack treatment. Twelve male subjects (average age 21 years) completed the following three testing conditions 24 to 48 hours apart: 30 -minute ice pack treatment, 15 minute treadmill exercise followed by 30 -minute ice pack, and 30 minute treadmill exercise followed by 30 -minute ice pack treatment. The intensity of exercise training was 60 to 80 percent maximum oxygen uptake for each of the subjects. Temperature probes were placed over the anterior talofibular ligament (ATFL) of each ankle, along with a crushed ice pack wrapped with a elastic wrap. Ice treatment temperatures were recorded at $2.5,5,10,20$, and 30 minutes, while the post-application temperatures, with ankle wrapped, were recorded at similar time intervals extending to 90-minutes. Mancuso and Knight found that the exercise conditions had non-significant higher 
temperatures (2.1 degrees), but this was not significant. The authors concluded prior exercise did not affect the rate of cooling in the ankle.

In a 1996 study, Palmer and Knight conveyed that most previous research had performed cryotherapy studies on non-exercising subjects, not addressing the effects pre-exercise had on the temperature of injured tissue. The purpose of their study was to examine the effects of repeated ice pack application on ankle and thigh skin temperature following exercise.

Twelve, physically fit, college-aged subjects (male and female) participated in the three testing conditions (20,30, and 40-minute ice-pack application) to the ankle and opposing thigh following a 15-minute bicycle exercise at 60 to 80 percent maximum heart rate. Thermocouples were attached to the thigh and anterior talofibular ligament (ATFL) of the ankle and the temperatures were monitored every minute using a electronic temperature device. Immediately following the first ice application $(20,30$, or 40 -minutes), the investigators had each of the subjects simulate showering and changing clothes with crutches using partial weight bearing gait. Following this 20-minute simulation, an elastic wrap was reapplied to the ankle and thigh for 40-minutes. One-hour had elapsed from the initial ice application, and a second ice treatment $(20,30$, or 40 -minutes) was applied. The testing was concluded following one-hour of the second treatment. Results indicated temperature during the first application and rewarming were greater during the 40-minute condition than the other conditions. Palmer and Knight (1996) concluded body parts warmed 
more quickly with the simulated activity (showering, changing clothes), and traditional protocol for reapplying ice to these acute injuries was too long. Effects of Cryotherapy on Joint Tissue

According to Evans et al. (1995), there were no prior studies of actual physical performance following cold application. With this in mind, these authors investigated the effects of ice immersion treatment on agility. The dominant foot and ankle of 24 non-injured male subjects was immersed in a one degree Celsius ice bath for 20 minutes. Following the treatment, the subjects performed three agility tests: a carioca maneuver, a cocontraction test, and a shuttle run within nine minutes of the treatment. All agility tests were conducted in a gymnasium, and the treatment agility times were compared with the non-treatment agility times given during a prior testing session. Results indicated no difference in agility time scores between the ice immersion and control sessions. According to Evans et al. (1995), cold may have affected the sensory receptors for thermal and pain changes, but spared the sensory receptors for ankle proprioception. The authors concluded the application of cold could be used on the foot and ankle prior to strenuous exercise with no alteration in agility.

Shuler, Ingersoll, Knight and Kuhlman (1995) were also interested in identifying the effects of cold to the foot and ankle, but had chosen to focus on a phase of a cutting drill motion with subjects. The concern of the authors was that cold decreased neuromuscular functions and muscle spindle firing which could have negative effects on the ability to perform cutting 
maneuvers in activities. The 33 non-injured college subjects for this laboratory study received each of the following four treatments prior to testing on four different test days: ice to the foot and ankle, ice to the lower leg, ice to the foot and ankle and lower leg, and no ice (control). Three trials of a cutting motion were then performed on an ankle force platform, as the investigators measured peak lateral force, time to peak force, and total contact time. Shuler et al. (1995) found no differences in peak force or total time between treatments. However, time to peak force was affected with one group during one session. The authors concluded ice treatment to the lower leg, foot and ankle prior to maximal cutting motion did not affect peak force and total time.

Narodowy et al. (1996) also examined the effects of cooling the ankle prior to performance. They focused their study on determining how precooling affected reaction time and movement time. Twenty-four noninjured subjects (male and female) performed 15 trials on a Dekan Performance Analyzer following four separate treatment conditions: cooling the ankle joint, cooling the peroneal muscle group, cooling the ankle and peroneals, and no cooling (control). The Dekan Performance Analyzer had the heel planted, but allowed forefoot movement on two different switch plates as subjects reacted to visual stimuli. Cooling prior to testing increased reaction time for peroneal $(5.8 \%)$ and ankle/peroneal $(10.2 \%)$, and it had the same effect on movement time with ankle $(2.9 \%)$, peroneal $(7.5 \%)$, and ankle/peroneal (17.3\%) pre-icing. 
From the results of this study, the authors concluded that an athlete's ability to perform simple movements or react to visual stimuli in sport was affected by pre-icing.

Cross et al. (1996) conducted a study to determine how functional performance was affected by ice immersion. The authors acknowledged the concerns of many health care practitioners regarding cryotherapy's depressive effects on physiological systems and motor activity in the body. Twenty, noninjured athletes from Division III football and soccer teams were assigned to either an experimental or control group. Both groups performed three trials of functional performance tests: the shuttle run, the 6-meter hop test, and the single-leg vertical jump. The treatment group received a 20-minute whirlpool ice immersion (13 degrees Celsius) to the lower leg, while the control group rested with no cold treatment. Results indicated the cold treatment to the lower leg caused a significant reduction in vertical jump scores and significantly slower shuttle run times. Cross et al. (1996) had also observed the cold treatment subjects had difficulty maintaining balance on the treated extremity. The authors concluded the possible consequences of cold therapy should be considered by athletic trainers before returning an athlete to competition.

According to Knight, Okuda, Ingersoll and Edwards (1997), there has often been confusion regarding the effect ice would have on muscle force during physical activity. The purpose of their study was to identify a possible relationship between muscle force and nerve conduction velocity following 
cold applications. Ten subjects appeared on two separate test days (ice and control) to determine how motor nerve velocity and muscle force in the forearm were affected. Two crushed ice packs were wrapped around the forearm of each subject with a six inch elastic wrap, and motor nerve velocity and muscle force were recorded at different times (before treatment and 0, 20, 40 , and 60 minutes following treatment) using a Biopac analyzer/amplifier with eight millimeter electrodes (ulnar and median nerve) and hand held dynomometer, respectively. Results indicated the ulnar nerve conduction was significantly less at 0,20 , and 40 minutes following ice application, and significantly less at zero in the median nerve. The authors found no difference in muscle force, and indicated that nerve conduction velocity immediately after ice application had gradually returned to normal.

Coppin et al. (1978) examined the effects of forearm, ice water immersion on handgrip strength. Fourteen male and female subjects (ages 22-52 years) participated in one test a week (no cold bath, left arm cold bath, and right arm cold bath) in a random order for three weeks.

For the cold treatment, the forearm was immersed in a 10 degree Celsius ice bath for 20-minutes, and grip strength was tested before and every twenty minutes following the treatment (4 hours) using a handgrip dynamometer. Skin temperature and blood pressure in the arm were monitored for all conditions using a thermistor and sphygmomanometer, respectively. Ice water immersion caused a significant decrease in handgrip strength in the both arms tested with all subjects (male and female), and required up to 40 
minutes to regain pre-treatment grip strength scores. The authors found no evidence of increased handgrip strength scores following treatment.

The results from a study by Barnes and Larson (1985), however, were quite different from those by Coppin et al. (1978). Barnes and Larson (1985) had also examined the effects ice water immersion had on grip strength. Twenty-four male subjects (ages 22 to 33 years) were randomly divided into either a cold treatment or heat treatment group. Skin surface temperature probes were attached along the forearm flexors, and three 3-second maximal isometric contractions using a handgrip dynamometer served as the pretreatment scores. The forearm was then placed in a specially constructed plexiglass cylinder with a latex membrane in which ice or hot water flowed, making contact with the forearm. The cold treatment consisted of 30 minutes at ten degree Celsius, while the heat treatment was 30 minutes of 40 degree Celsius. Subjects performed one, maximal grip contraction every two minutes during treatment. Barnes and Larson found the cold both inhibited and facilitated maximum grip strength, and this was dependent on the time of cold exposure. During the initial cold treatment, the investigators found an increase in maximum grip strength ( 8.29 percent), but this decreased (14.05 percent) at the conclusion of treatment. The authors concluded cooling caused the cutaneous receptors to suppress afferent discharges which led to inhibition of motor-neuron pool occlusion, allowing greater motor output. 


\section{Loint Proprioception following Cryotherapy}

Thieme et al. (1996) examined how knee movement reproduction was affected by a 20-minute ice pack application. Thirty-seven, non-injured subjects (16 female and 21 males) participated in two testing sessions and under two conditions: a 20-minute application of ice and control. The subjects sat blindfolded on a Kinetic Communicator Dynamometer (KinCom) and were tested on the ability to accurately replicate passive knee range of motion: 90 to 60,60 to 30 , and 30 degrees to full extension. Results indicated proprioceptive ability to judge and replicate passive knee motion did not differ between the ice treatment and control session. The authors conveyed the 20-minute ice treatment did not cool the nerve enough to alter proprioceptive transmission. Thieme et al. (1996) advocated cryotherapy to facilitate rehabilitation exercises without concern or fear of decreased proprioception causing re-injury.

The purpose of a study by Ingersoll et al. (1992) was to examine how sensory perception in the ankle was affected by hot and cold treatments. The authors had conveyed hot and cold modalities were used on athletes prior to therapeutic exercise with no clear information regarding its effect on sensory perception. Twenty-one uninjured subjects reported to a laboratory on three separate dates to receive the following 20 minute treatments: one degree Celsius ankle immersion, a 40 degree Celsius ankle immersion, and quiet sitting (control). Ingersoll et al. (1992) obtained data from three different tests on the treated and contralateral foot: a blindfolded topagnosis test at the sole 
of the foot, a two-point discrimination at the sole of the foot, and a timed onelegged balance test (stork stand). Results of this study indicated no significant differences between the three treatments. The authors concluded these hot and cold modalities could be used prior to therapeutic exercise without sensory perception being altered.

A similar study was conducted by Brooks, Ingersoll and Knight in 1995 to determine how cryotherapy and thermotherapy affected the ability to perceive forces placed on the ankle. Thirty subjects (ages 18 to 30 ) were randomly divided into three different groups: a one degree Celsius ice immersion group, a 40 degree Celsius warm bath group, or a rest (control) group. The right ankle of each subject was placed in the everted position on an ankle exerciser, two different weights were placed on the machine as subjects were asked to eccentrically lower the weight. For the three days of testing, the subjects on each day made five weight comparisons trying to determine the heavier weight. Brooks et al. (1995) concluded that all of the modalities tested did not affect ankle baragnosis, and could be utilized prior to exercise.

LaRiviere (1994) had similar results when investigating the effect of ice immersion on the position sense of the ankle. LaRiviere used 30 uninjured subjects ( 21 females, 10 males) that were randomly placed in three different pretest condition groups: no ice immersion, five minutes of ice immersion, and 20 minutes of ice immersion. The ankle attachment of an Orthotron II was used for the subjects to replicate two ankle positions in mid-range. 
Eight repositioning trials (four for each angle) were performed after the pretest conditions. The author found no statistically significant difference between angles, trials, conditions, order of pretest conditions or gender. The ankle receptors solely responsible for joint position sense, according to LaRiviere, were resilient to the five and 20 minute ice immersion treatments. The author had also indicated these unaffected joint receptors had compensated for affected receptors (i.e., muscle receptors and skin) during the testing.

\section{Neurophysiclogy of Joint Proprioception}

In a 1997 study, researchers (Lephart, Pincivero, Giraldo and Fu) defined proprioception as a specialized variation of the sensory modality to touch that encompassed the sensation of joint movement (kinesthesia) and joint position (joint position sense). These authors identified skin, muscles, ligaments, and joints as sensory contributors in providing afferent information to the central nervous system (CNS) regarding the loading and deformation of tissues. According to Lephart et al. (1997), stimulation of these mechanoreceptors by loading or deformation sent information via the peripheral nervous system (PNS) to the CNS to generate a response from three levels of motor control: spinal reflexes, cognitive programming, and brainstem activity. This neuromuscular feedback mechanism, according to the authors, was developed by repeated voluntary movements being stored as central commands due to cognitive programming by the CNS (motor cortex, basal ganglia, and the cerebellum). This kinesthesia and proprioceptive 
feedback provided awareness (conscious or unconscious) of motion from a limb or joint, according to the researchers. They also concluded that injury or trauma to a joint caused partial deafferentation to the mechanoreceptors which brought about possible proprioceptive deficits. In addition, injured athletes, they claimed, needed to regain the neuromuscular control before returning to competition, to avoid susceptibility to re-injury.

Rowinski (1990) stated the connection between the peripheral nervous system's (PNS) joint mechanoreceptors and the CNS functionally helped protect the joint from damage by detecting excessive end-range of motion. According to Rowinski (1990), this was done by the joint's micromechanical status quickly and accurately conveying information to the CNS to (1) influence motor activity responsible for regulating joint position, angle and aperture; (2) influence motor neurons that controlled coordination and patterns of muscle activity in the joint; (3) influence neural pathway activity responsible to controlling perceptions related to awareness of joint status. Rowinski (1990), however, also indicated muscle spindle receptors were more involved in position sense than the actual joint receptors in capsule or ligamentous tissue. In fact, very few joint receptors were found to be dynamically or statically activated at mid-range of motion, according to Rowinski (1990).

Grigg (1994) also indicated sensory neurons in muscle played an important role in joint proprioception, but without the other afferent receptors (skin, joint, ligament) simultaneously activated, proprioceptive 
acuity was poor. According to Grigg (1994), normal proprioception was dependent on more than just muscle sensation to joint position. In his 1994 article, Grigg examined all current evidence of the role various sensory neurons contributed to proprioception. Most of the article focused on the function of mechanoreceptors located in skin, joints (capsule), ligaments, muscle and tendons. In describing joint mechanoreceptors, Grigg identified Ruffini afferents as capsular-stretch sensitive receptors involved in sensing joint rotation, and primarily served as joint range limit detectors. Paciniform afferents were another form of receptor around the joint capsule, but compression sensitive to joint rotations with the end-range of joints. Grigg had also included free-nerve endings (nociceptors) as fine (small) afferents that primarily contributed to sensing forceful joint movements into endranges and also noxious joint rotations. Grigg concluded proprioception was a complex combination of sensations mediated by all the above mentioned sensory neurons, and important in protecting the integrity of unstable joints.

In a 1982 study, Newton examined the contributions joint receptors had on reflexive and kinesthetic responses. Similar to Grigg's 1994 study, Newton (1982) had also identified Ruffini, Pacinian and GTO-receptors as important contributors to joint proprioception by dissecting the knee joint in cats. Ruffini receptors (Type I) were found primarily in the capsule and ligament of proximal joints with ability to detect direction and speed of movement. The Pacinian receptors (Type II) were more commonly found in the synovial membrane of capsule and fat pads in distal joints, and served in 
detecting small and accelerating movements. Golgi tendon organs were the Type III receptors which were found in collateral ligaments of joints. Newton described these Type III receptors being responsive to only active joints during active or passive motions into extreme end ranges. The Type IV receptors were the free-nerve endings (nociceptors) which were pain receptors that detected direct chemical irritation or responded to extreme mechanical deformation.

\section{Effects of Joint Injury on Proprioception}

Glencross and Thornton (1981) indicated direct injury could distort proprioception necessary for the control and timing for skilled performance. These authors also conducted a joint replication study to determine how injury to the ankle joint affected position sense. Twenty-four athletes (male and female) with prior ankle injuries (at least eight months prior) were placed in groups according to their severity of injury: severe injury; moderate injury; and mild injury. Following a questionnaire for demographic information, the subjects were placed in supine and the ankle was positioned at 110 degrees. The ankle was passively moved by the experimenter in one of four ankle positions $(105,120,130$, and 140 degrees) with movement commencing from 110 degrees. A goniometer was used to measure joint angle replication. The testing order for ankle position was randomized as each subject performed five test trials for each position. The authors also counter balanced testing for the injured versus non-injured ankle. 
Results indicated a linear trend between the degree of error and joint angle. Most errors of joint replication occurred at the largest angles of movement. Glencross and Thornton also found the severely injured group had the greatest error, while the mildly injured group had the least amount of error. The most common error joint range was at 140 and 130 degrees. The authors indicated injury damaged the total number of cells necessary for sensing terminal joint positions, and affected proprioception required for effective skilled actions.

Gross (1987) performed similar joint position replication tests on subjects, but investigated how proprioception was affected by recurrent ankle sprains. The author questioned previous literature indicating joint receptors were major contributors to joint position sense. Twenty-one males and females (average 20.8 years) were distributed into three groups for testing: recurrent lateral ankle ligament sprains (Group 1), contralateral nonsprained ankle of Group 1, and non-injured ankles (Group 3). The subjects performed six trials of active and passive movement while blindfolded on a Cybex II isokinetic dynamometer. The ankle was placed in the testing positions (10 of eversion, 10 of inversion, and 20 of inversion) for 15 seconds, and the subjects were then asked to replicate these positions (actively and passively) after the experimenter had moved the ankle into end-ranges of inversion and eversion. Passive joint replication by the subjects was better than active, and Gross found no significant effect caused by injury. Rather than acting as a major contributor to joint position sense, Gross concluded these joint 
receptors were more involved in fine judgment/detection of joint angle while muscle receptors were utilized more for actual joint movement.

Lentell, Baas, Lopez, McGuire, Sarrels and Snyder (1995) examined three contributing factors to functional instability of the ankle.

Proprioceptive deficits, muscle function and anatomic laxity had never been investigated together to determine involvement in functional stability. Thirty-four college students (male and female) diagnosed with ankle instability (three months to 16 years) were solicited from recreational activity classes. The involved and uninvolved ankle of each subject received inversion stress radiographs, and were evaluated for both passive movement sense and peak torque. The inversion stress radiographs were taken and interpreted with the radiologist blinded to side of involvement. For the testing of passive movement sense, each subject was seated with the foot resting on an ankle platform device which moved by electric motor and rotated the foot on an axis at 0.3 degrees per second. Subjects were blindfolded while listening to music on a headset, and instructed to shut-off a hand-held switch whenever movement of the platform was sensed. Three trials were performed for each foot, and the investigators recorded the angle in which the movement was sensed. A Cybex II+ isokinetic dynomometer was used to evaluate peak torque with each subject seated and using a foot-plate. Six maximal repetitions for inversion/eversion movements were performed at $30,90,150$, and 210 degrees per second with a 30-second rest period between each exercise. Results indicated a significantly greater degree of talar tilt and 
passive movement sense with the involved ankles, but no significant differences in eversion strength between the involved and non-involved ankle. Lentel et al. (1995) concluded proprioceptive deficits and anatomic laxity were greater concerns for managing instability than strength.

Researchers in a similar study (Lentell, Katzman and Walters, 1990) found proprioceptive deficits to be more of a factor, than muscular weakness, with chronically unstable ankles. Lentell et al. (1990) examined strength, but went a step further by balance testing to measure instability. Thirty-three male and female subjects (ages 17-54) with mild ankle instability were solicited for the study. Each subject performed a modified Romberg test by balancing on each foot for 5-10 seconds with eyes open, and repeated with eyes closed. Subjects were observed for ability to balance, and later asked for the level of difficulty between injured and non-injured leg. Peak torque was then measured for inversion/eversion using a Cybex II+ Isokinetic Dynomometer at 30 and zero (isometric) degrees per second. Six reciprocal (inversion/eversion) repetitions at 30 degrees, and three of maximal isometric inversion and eversion each were recorded. The authors found no significant weakness in the chronically unstable ankles. However, 55 percent of the subjects had balance asymmetries between the involved and uninvolved ankle. A balance deficit was found in 94 percent of the involved ankles of the subjects ( 55 percent) that had deficits. Lentell et al. concluded the factor contributing to instability for over one-half the subjects may have been proprioceptive deficits. 
Garn and Newton (1988) conducted similar experimental tests to determine the impact multiple ankle sprains had on kinesthetic awareness. Thirty midshipmen (male and female) of the United States Naval Academy, with a history of two or more lateral ankle sprains, were used for the study. The involved and uninvolved ankle of each subject was tested for kinesthetic awareness by performing a passive movement and standing balance test. For passive movement testing, each subject was seated with the testing foot resting on a kinesiometer. This moveable platform simulated movement patterns for ankle dorsiflexion and plantar flexion, and was controlled manually by the experimenter. As each ankle was randomly selected for testing, all subjects performed 30 trials of attempting to detect passive ankle movement occurring at 0.3 degrees per second. A screen obstructed each subject's view, and no passive movement occurred during 15 of the trials. Lucy's choice theory measurements (hit rate, false alarm rate, sensitivity, and response bias) were used as the subjects responded "yes" or "no" to whether passive movement had occurred. This was used to determine possible subject bias with responses. Standing balance was also tested for the involved and uninvolved ankles by observing a 30 second balance test with eyes opened and closed. The independent observer was unaware of which ankle, for each subject, was injured. Results of this study indicated passive movement for the involved ankle was significantly poorer, and there was a greater amount of balance deficits with the one-legged balance test. 
Forkin, Koczur, Battle and Newton (1996) applied the same framework of Garn and Newton's (1988) study to gymnasts with unilateral ankle sprains. The purpose of their study was to determine if these gymnasts had decreased ankle proprioception and balance deficits. Forkin et al. (1996) used the same kinesthesiometer as Garn and Newton (1988) to test passive plantar flexion in 11 male and female gymnasts (16 to 22 years of age). The injured and uninjured ankles of these gymnasts were also randomly tested with the platform being passively moved from neutral to 5 degrees of plantar flexion. Thirty, random movement and non-movement, test trials were performed while subjects responded "yes" or "no" to perceived passive ankle movement. Lucy's choice theory was used to detect subject bias. Forkin et al. (1996) also used the same one-legged balance test as Garn and Newton (1988) to compare the degree of kinesthesia in both ankles. The results of their study supported the findings of Garn and Newton (1988). Passive ankle movement sense (hit rate) for the injured ankle of these gymnasts was significantly decreased $(142 / 165)$ when compared with the uninjured side $(158 / 165)$. The authors concluded the decreased passive movement sense was due to partial deafferentation caused by ankle injury.

De Carlo, Rettig and Talbot (1986) also claimed that trauma to tissue caused deafferentation which resulted in proprioceptive deficits. Realizing the anterior talofibular ligament (ATFL) was the most commonly sprained ankle ligament, the authors' purpose was to determine how a Xylocaine (anesthetic agent) injection to the ATFL would affect joint proprioception. 
The 38 subjects (male and female) for this pretest/posttest design had no prior lower extremity injuries, and were placed into either a test group or control group. All subjects were blindfolded and performed five, 30-second pretest balance trials on a multiaxial balance evaluator (MABEL). This ankle disc system allowed for ankle movement in all axes of motion, and allowed double-limb support for the test. Sensors along the perimeter of the contact plate measured time and frequency in which subjects were out of balance. Fourteen of the 38 subjects then received a five cubic centiliter of Xylocaine (anesthetic agent) injection to the anterior talofibular ligament (ATFL), and immediately followed-up with a posttest identical to the pretest. The investigators found a statistically significant difference existed between preinjection and post-injection status. Six of the seven injected males had improvements in balance times, while two of seven females had an average increase for balance time. De Carlo et al. (1986) concluded joint proprioception was not affected by anesthetic injection, and that learning actually occurred with the trials.

A similar study was conducted by Barrack, Skinner, Brunet and Haddad (1983), but examined how intraarticular knee anesthesia affected functional performance. It was a double-blind experiment in which subjects had received ten cubic centiliters of either two percent Lidocaine or sterile saline, prior to being examined in a pretest/posttest manner. These investigators first analyzed gait for ten uninjured male and female subjects (average age 28 years) using a footswitch stride analyzer. Average cadence, stride length, and 
gait cycle were determined, by examining frame-by-frame images obtained from a video camera. Knee motion and gait were then measured and plotted on the frame-by-frame images. Joint position sense was then analyzed with each subject seated, and with lower legs hanging freely. Inflated custom-made Jobst air splints were fitted above and below the knee joint to eliminate any cutaneus sensation. Starting position for the blindfolded subjects was 90 degrees of knee flexion, as the pulley of a slow speed motor shaft passively moved to a random angle from the starting position. The investigators recorded ten repetitions (five on each leg) to determine accuracy for the reproduced movements. Threshold to passive motion was then measured by having the subjects detect joint position change. Again, ten repetitions (five each leg) were performed, and subjects used an on-off switch to confirm when joint position had changed. Barrack et al. (1983) found no difference in proprioception measurements and no functional deficits in ambulation when comparing pretest and posttest (Lidocaine or sterile saline) results.

Borsa, Lephart, Irrgang, Safran and Fu (1997) examined knee proprioception in anterior cruciate ligament (ACL) deficient athletes. These authors, like Barrack et al. (1983), were attempting to determine the degree to which sensory (afferent) feedback mediated joint position. The 29 ACLdeficient subjects (ages 10-50 years) for this study had been injured, received post-injury rehabilitation for an average of two and one-half months, and were tested $41.7 \pm 11.7$ months (range 2 to 228) after injury. Borsa et al. (1997) tested joint position sense in an identical manner to Barrack et al. (1983) by 
having the blindfolded subjects manipulate an on-off switch when passive motion was perceived. Pneumatic compression sleeves were also used on both feet, and a digital microprocessor counter measured angular displacement for a motor-driven movable shaft. The investigators randomly tested proprioception from starting positions of 15 degrees of knee extension and 45 degrees of knee flexion for both legs. Functional performance was measured by having each of the 29 subjects perform a single-legged hop test for forward horizontal distance. The best score of three trials was recorded in centimeters and analyzed with the results of the proprioception measures. Results indicated threshold for the ACL-deficient knee to passive motion moving into extension from 15 degrees was significantly lower than moving into flexion, and also lower than at 45 degrees. The authors concluded proprioception in ACL-deficient knees was more sensitive with approaching end-ranges of extension than moving into flexion.

Dvir, Koren and Halperin (1988) claimed contributions from the ACL in knee proprioception were secondary, and that knee musculature primarily controlled for position sense. These authors studied joint position sense in 25 subjects (male and female) that underwent $A C L$ reconstruction after complete ACL tears. Time between surgery and testing ranged from averaged 12.2 months, and the authors tested for position sense in the same seated manner as Borsa et al. (1997) and Barrack et al. (1983). Test positions were 20 to 40 degrees and 50 to 70 degrees, and each of the blindfolded subjects were tested in four different modes: passive, concentric, dynamic and eccentric. 
Eight tests for both legs were performed at these four modes, and were monitored and measured by a potentiometer and digital multimeter, respectively. Results indicated errors in joint position sense primarily occurred in the passive mode, and categorically followed with the dynamic, concentric and eccentric modes. In contrast to results found by Barrack et al. (1983), these authors found proprioception in the knee was not affected with neural input to the ACL eliminated. There were also no differences when comparing scores between operated and normal knees.

In a similar study, researchers (Guido, Voight, Blackburn, Kidder and Nord, 1997) examined the effect of chronic effusion on knee joint proprioception. A 48-year-old male concluded rehabilitation for a knee injury, and served as the single-subject for this case study. A Biodex dynamometer was used to measure the blindfolded subject's three trials of active and passive joint reposition ability. Immediately following the trials, 60 cubic centiliters of fluid were aspirated from the subject's knee, and the active and passive trials were repeated. The experiment concluded with a 24hour posttest using the same protocol. The knee joint effusion diminished proprioception for repositioning active and passive joint movements. Aspiration of the subject's knee did not improve proprioception, and this effect continued 24 hours post-aspiration. Guido et al. (1997) suggested athletes returning to competition with chronic joint effusion had an increased risk of re-injury due to proprioceptive deficits. 
Lessard, Scudds, Amendola and Vaz (1997) investigated the efficacy of cryotherapy application on post-surgical knees. Forty-five male and female patients (ages 20 to 75 years) with various knee diagnoses (osteoarthritis, meniscal tears, chondromalacia, arthrofibrosis, loose bodies, and plica) underwent arthroscopic surgery (less than 40 -minutes) by one of three experienced orthopedic surgeons specializing in knee arthroscopy. Prior to surgery each subject was randomly placed into Group 1 (20-minutes pre-icing followed by home exercise program) or Group 2 (home exercise program only) for a one-week program performed four times per day. Following hospital discharge, patients received a 30 tablet Tylenol prescription to be taken every four hours as needed. Patients used a diary to document compliance with the home program, use of medication, and the amount of pain experienced with the one-week program. The authors of this study found no significant differences between the two groups for knee range of motion, knee girth, isometric quadriceps strength, pain or point tenderness. Lessard et al. (1997) concluded cryotherapy was effective in improving exercise compliance, decreased medication consumption, and improved weight bearing following arthroscopic surgery.

Another group of researchers (Birmingham, Chesworth, Hartsell, Stevenson, Lapenskie and Vandervoort, 1997) examined the mechanical and neuromuscular processes related to recurrent ankle sprains, and had similar findings as Lentell et al. (1990). The purpose of their study was to compare 
maximum inversion range of motion and peak passive strength in the involved and uninvolved ankles of subjects with recurrent ankle sprains.

Thirty male and female ( $20-40$ yrs old) subjects that had received previous treatment for inversion sprains were positioned in supine for six measurements on the Ankle Stress Testing Apparatus (University Mechanical Shop, London, Ontario, Canada). The investigators measured for a baseline resistive torque with the foot at zero degrees inversion, and then passively rotated to maximum inversion at less than five degrees per second. Six measurements for peak torque of the evertor muscles were recorded from zero degrees to painful, passive end-range of inversion. The authors indicated that this, although painful, simulated the clinical inversion test. Birmingham et al. (1997) found no differences between the inversion range of motion and peak torque for the involved and uninvolved ankle at maximum passive inversion.

\section{Functional Testing for the Lower Extremity}

A majority of the current literature regarding joint proprioception obtained valuable information from primarily laboratory studies, rather than sport simulation or field studies. This available research regarding functional agility following ice-pack application has been utilized by some athletic trainers in an applied fashion with no clear understanding of the possible effects on performance. Athletic trainers, however, have utilized various forms of lower extremity performance tests to determine whether an injured athlete was ready to return to play. 
The performance tests used by Tegner, Lysholm, Lysholm and Gillquist (1986) were the one-leg hop, figure of eight running, running up and down a spiral staircase, and running up and down a slope. The purpose of their study was to evaluate the performance of ACL injured (26 males) and uninjured (66 males) soccer players between the ages of 23 to 33 years. All soccer players were from various division levels of the Swedish National League. The 26 subjects with ACL injuries had all tested positive for instability on evaluation, and had undergone arthroscopy at least two months prior to testing. Following a ten minute ergometer cycle warm-up, each of the subjects then performed the one-leg hop, figure of eight running, staircase running, and slope running. The investigators also evaluated each subject's quadriceps strength using a Cybex II Dynamometer. Quadriceps strength was tested isokinetically at 30 and 180 degrees per second, and isometric testing at 60 degrees of knee flexion. Tegner et al. (1986) had indicated this variety of performance tests, placing stress on the leg in different ways, was a valuable method for determining an athlete's functional status following injury. The injured soccer players hopped significantly shorter distances and ran the figure of eight significantly slower than the uninjured soccer players. The injured soccer players also ran the stairs and slope running significantly slower. The authors concluded the performance tests used in the study were effective for evaluating and monitoring an athlete's condition.

Bolgla and Keskula (1997) also found the single leg hop test to be a reliable measure for determining the level of lower extremity function in 
athietes. The concern of these investigators was ensuring that sports medicine clinicians had reliable functional performance tests for evaluating an athlete's return to play status. According to Bolgla and Keskula, there was limited research available regarding the reliability of lower extremity performance tests. Twenty uninjured male and female subjects (ages 20 to 28) performed three trials of each of the following tests: a single-legged hop for distance, a single-legged six meter timed hop, a single-legged triple hop for distance, and a single-legged cross-over hop for distance on two different days in a random testing order. Three practice trials were given for each test, and the dominant leg was used and determined by asking each subject which foot they would use to kick a ball. Average scores for the functional performance tests on days one and two were analyzed and indicated the three practice and test trials were statistically the same within the six trials. The single-legged hop for distance had the highest test-retest reliability (.95 to .96$)$ in testing the intraclass correlation coefficients, and the investigators conveyed this was due to subjects subjectively appearing more confident with it over the other tests. The authors concluded the four tests used in the study were reliable measures for evaluating lower extremity functional performance, but emphasized the importance of determining optimal practice trials and maintaining a standardized protocol to maintain the reliability of each test.

In a 1996 study, researchers (Keskula et al.) examined functional outcome measures for knee dysfunction assessment. The authors, similar to Bolgla and Keskula (1997), were also concerned with clinicians having 
effective tests for assessing an athlete's level of impairment, rather than simply answering the question, "Can they return to play ?". The authors recommended both psychometric questionnaires and performance tests be administered to injured athletes as functional outcome measures for determining when return to play or movement into the next phase of rehabilitation was appropriate. For the psychometric tests, questions regarding level of function were devised in a Lysolm scoring style, activity scores (level 1-10), and subjective knee score questionnaire. Keskula et al. (1996) recommended examining each questionnaire for content validity before using it to measure outcome.

\section{Summary and Proposal}

The literature review presented most of the current available research regarding the utilization of cryotherapy as an effective therapeutic modality in sports medicine today. Cryotherapy has become one of the most common treatments in sports medicine (Merrick et al., 1993), yet there has been much confusion regarding its use in treating acute and chronic injuries (McLean, 1989). The question is whether the practice of pre-icing an injured athlete, prior the therapeutic exercise or competition, influences functional performance. Some researchers (Evans et al., 1995) are uncertain. Ice packs with a compression wrap are effective for causing analgesia (Bugaj, 1975; Merrick et al., 1993; and Starkey, 1976) and the reduction of swelling (Bugai, 1975; LaRiviere, 1994). The analgesia allows certified athletic trainers to initiate early range of motion (Bugaj, 1975), prevents muscle atrophy 
(Hocutt et al., 1982) and facilitates the healing process (Starkey, 1976). Some believe that pre-icing before a skilled performance may distort the ability to acknowledge sensory stimuli (LaRiviere, 1994) which could predispose an athlete to injury, and the specific effects on sensory perception are not clear (Ingersoll et al., 1992). Proponents (Brooks et al., 1995; LaRiviere, 1994; Starkey, 1976) of pre-icing claim that joint receptors were not significantly affected. According to LaRiviere (1994), the receptors responsible for joint position sense compensate for the affected receptors during 20-minute ice immersion treatments. Opponents to pre-icing (Barnes \& Larson, 1985; Coppin et al., 1978), on the other hand, conveyed athletes were susceptible to reinjury (Lephart et al., 1997) due to deafferentation caused by injury (Forkin et al., 1996) and balance deficits (Lentell et al., 1990). A majority of the previous studies were conducted in laboratories where researchers investigated cryotherapy's effect on muscle strength (Barnes \& Larson, 1985; Coppin et al., 1978) and balance tests using laboratory equipment (Gandevia \& McCloskey, 1976; Glencross \& Thornton, 1981). For many certified athletic trainers, the current literature is not clear on whether an athlete could safely return to play immediately following cryotherapy. Evans et al. (1995) and Cross et al. (1996) both examined cryotherapy's effect on functional performance with the use of ice immersion. There were conflicting results when the two studies were compared, leaving certified athletic trainers with no accurate guidance for implementing an effective pre-icing protocol. This research study modeled the laboratory investigations by Evans et al. (1995) 
and Cross et al. (1996), but more effectively simulated the typical setting in which athletes perform. It was the intent of this researcher to provide certified athletic trainers with more pertinent information regarding the effect of pre-icing on functional agility. 


\section{Chapter 3}

Methods and Procedures

The purpose of this study was to determine the effect of ankle cryotherapy on three functional agility tests. This chapter content conveys a detailed description of the methods and procedures in which the subjects and instrumentation were utilized by the researcher. The overall research design and methods for analyzing the data are also described in this chapter.

\section{Subjects}

Twenty-two intercollegiate athletes, 10 male and 12 female, from West Valley College in Saratoga, California voluntarily served as the subjects for this study. The intent was to test outdoor-sport athletes that required a high degree of agility to perform on an uneven surface (grass field) wearing turf or cleated shoes. Some of the prior agility studies using cryotherapy (Cross et al., 1996; Evans et al., 1995) were conducted in a laboratory or gymnasium setting with athletes wearing tennis shoes and being tested on smooth, flat surfaces. Following approval from San Jose State University's Human Subjects Committee (Appendix A), the head coach for each of the intercollegiate teams held a team meeting in which the researcher invited and encouraged athletes to participate in the study. Athletes interested in participating in the study signed their names on a sign-up sheet (Appendix B) and a consent form (Appendix C), agreeing to participate in the study. A questionnaire (Appendix D) was then filled-out by all prospective subjects to determine health status, previous injuries, history of cryotherapy treatments, years of experience in 
sport, collegiate eligibility year, age, and gender. The completed questionnaires were then collected by the researcher and reviewed. Subjects indicating any prior ankle injury within six months of the first testing day were removed from the subject pool by the researcher. Furthermore, prospective subjects that reported any current neurovascular diagnosis or equilibrium disorders were also removed from the subject pool. This reduced the risk of possible injury or neurovascular damage from the effects of the experiment being conducted. The name of each participating subject was then written on a folded $3 \times 5$ card and placed in one of two appropriate sealed boxes marked "Male Subjects" and "Female Subjects". The top of each box had a thin slot to accommodate the $3 \times 5$ cards. The blindfolded researcher then randomly pulled an equal number of male and female ( $3 \times 5$ cards) subjects from each box. The first names pulled from both boxes were designated male and female treatment subjects, while the second pulled from the male and female boxes were designated as control subjects. This alternating pattern determined the equal number of male and female (treatment and control) subjects. A "control group" or "treatment group" adhesive sticker was then added to side one of each subject's $3 \times 5$ card, and the cards remained grouped according to male/female and treatment/control. To counterbalance the three functional agility tests, a large ( $3 \times 5$ foot) cardboard Testing Sequence Board (Appendix E) was used to determine the sequence in which each treatment or control subject was to perform each of the three functional agility tests. 
Five of the Male Treatment subject cards were shuffled by the researcher and then distributed face-down onto the Male Treatment portion of the testing sequence board working from top to bottom, filling all available sequences spaces (Appendix E). The five, $3 \times 5$ cards, for the Male Control subjects were shuffled and distributed on the sequence board in the same manner. The six Female Treatment and six Control subjects were also shuffled by the researcher and distributed appropriately on the sequence board face-down. The researcher then turned over each of the $3 \times 5$ cards to determine the testing sequence for each of the subjects, and a sticker indicating each subject's testing sequence was placed on side two of his/her $3 \times 5$ card. Throughout the research testing, an identification number for each subject was used rather than names in order to maintain confidentiality. All information on each subject's $3 \times 5$ card was then recorded on the appropriate forms. The subjects were then informed, by their respective coach, the two dates to appear for experimental testing. The $3 \times 5$ cards were issued to each subject by his or her coach as a reminder for the testing days. The $3 \times 5$ ticket also had a note instructing subjects to wear a shirt, shorts and turf or cleated shoes for the testing.

\section{Instrumentation}

Two quarts of crushed ice in a one-gallon Ziplock bag was used along with a 6 inch by 6 foot elastic wrap for ice application, similar to Mancuso and Knight's 1992 study. Some of the earlier studies used ice water immersion (Cross et al., 1996; Evans et al., 1995) prior to functional agility testing. The 
intent was to simulate the sidelines of a game field in which certified athletic trainers more commonly used ice packs and compression wraps for athletic injuries. Two treatment tables were located on the sideline of the football game field at West Valley College and provided the researcher with stations for the treatment. The functional agility testing equipment included: 20 fluorescent cones, two stopwatches (Sportline, Model 220, Campbell, CA) two tape measures and two testing assistants to time the agility tests, monitor stations and record the data on the Functional Agility Test Daia Sheet (Appendix F). All functional agility tests modeled designs of previous researchers (Cross et al., 1996; Evans et al., 1995; Keskula et al., 1996; and Tegner et al., 1986) as mentioned in Appendix G.

\section{Research Design}

The 22 volunteer subjects appeared for the first testing day at the West Valley College football field. A single limb hop for horizontal distance was performed by each subject to determine his/her non-dominant leg (Appendix G). The single limb hop for distance is a standardized functional performance test (Borsa et al., 1997), and was used in prior studies (Bolgla and Keskula, 1997; Keskula et al., 1996) to assess lower extremity function. Each of the 22 subjects were instructed to stand on one leg behind a painted line on the football grass field and asked to hop forward for maximum horizontal distance. Arm swinging for momentum was permitted. Distance was measured, using a tape measure, from the painted line to the spot in which the heel of the foot landed. Following two practice hops for the right and left 
leg, an average score was obtained from three trials for each subject's right and left leg. Colored golf tees were inserted into the turf at the point each subject's heel made contact. The lower average score was determined for each subject's non-dominant leg to be tested. The researcher at this time entered each subject's testing leg on the Subject Roster Form (Appendix H). Subjects then followed the agility testing sequence written on his/her $3 \times 5$ card by jogging 50 yards to their first functional agility test station on the testing field (Appendix I). During a 15-second calf stretch (Cross et al., 1996), subjects received verbal instructions and observed a demonstration of the functional agility test to be performed. Following one practice trial, all subjects had a 30second rest between three recorded trials, and a one-minute rest between each of the three agility tests, similar to the protocol by Evans et al. (1995). The functional agility test times were timed to the nearest tenth of a second with a stopwatch, and recorded on the Functional Agility Test Data Sheet (Appendix F) by the researcher. All functional agility tests were completed within ten minutes. Cross et al. (1996) completed agility testing within 20minutes of pre-icing, while Evans et al. (1995) completed similar agility tests within nine minutes. In a 1993 study, Merrick et al. found that neither deep temperature nor skin temperature returned to normal for either ice alone or ice with compression treatments when ankle temperature was examined 20minutes post-application. For this study, all functional agility tests were completed within ten minutes. 
On the second test day, the 22 subjects were divided into a control group or treatment group indicated by each subject's $3 \times 5$ card and the Subject Roster Form (Appendix $\mathrm{H}$ ). All subjects once again appeared at their scheduled test time, but the treatment subjects reported to the treatment area prior to functional agility testing. While the control group repeated the same procedures for the three functional agility tests, the treatment group received a 20-minute ice pack application to the lateral ankle of the testing leg.

Treatment was administered on the sidelines of the football field with each subject supine on a treatment table. The ice pack was applied to the lateral ankle joint, and compressed with the use of a six inch by six foot elastic band wrapped around the ankle. All ice pack applications were applied by the same researcher to maintain uniform positioning of ice pack and compression of elastic wrap. The lower leg was then supported on an ice chest for elevation. Immediately following the 20-minute treatment, the ice was removed and each subject jogged 50 yards to their respective functional agility testing station (according to testing sequence). Each subject was instructed to perform a 15-second standing calf stretch (Cross et al., 1996) while observing a demonstration of the functional agility test to be performed. Each of the treatment subjects, at his/her first testing station only, was asked how the ankle felt immediately following cryotherapy. This was similar to Evans et al. (1995) study in which subjects reported numbness, tingling, stiffness, or feeling awkward. The verbal responses were recorded by the researcher and provided the study with subjective information regarding any possible 
apprehension due to the effects of pre-icing. One practice trial for each test was performed, followed by three trials which were recorded by the researcher. The functional agility test times were recorded to the nearest tenth of a second with the use of stopwatches by the researcher. All field testing data sheets were then collected and analyzed for results by the researcher.

Statistical Analysis

The purpose of this study was to determine the effects of cryotherapy on three functional agility tests. It was hypothesized there would be no significant mean change in the pretest versus posttest scores for the treatment and control groups, male and female, tested. The alpha level for testing was preset at $p>0.05$. Mean scores from three trials of the three functional agility tests were calculated by the researcher to determine differences between the experimental and control groups for the male and female subjects. In this pretest/posttest design, the researcher analyzed the mean scores by performing independent $\mathrm{t}$-tests for the football (male) and soccer (female) subjects. Subjective responses from the treatment subjects, male and female, were also analyzed for determining what each subject felt during the agility maneuvers. Cross et al. (1996) used ice water immersion and a different set of functional agility exercises on a flat-even surface, but tested football and soccer athletes. Evans et al. (1995) tested the effect of ice immersion on three tests of agility (shuttle run, carioca maneuver, and cocontraction test), but tested subjects on a flat-even surface. It was the researcher's intent to test the same 
type of athletes as Cross et al. and Evans et al., but utilizing a testing surface (grass), turf shoes and agility tests that more accurately simulated the setting in which these athletes compete. 


\section{Chapter IV}

\section{RESULTS}

\section{Introduction}

The purpose of this study was to determine how pre-icing the lateral uninjured ankle affected performance on three functional tests of agility. Following the protocol of two previous studies (Cross et al., 1996; and Evans et al., 1995), this research tested the subjects on natural turf (grass) wearing turf shoes, rather than in the laboratory on flat-even surfaces. A secondary purpose of this study was to simulate, more authentically, a real game situation where ice packs with compression wraps are used to treat injuries. Results from research by Cross et al. indicated a reduction in agility scores and balance deficits with pre-icing football and soccer athletes, while Evans et al. found no significant difference in pretest - posttest agility scores testing subjects from intramural sports classes.

The results from these two pre-icing studies led to conflicting recommendations for athletic trainers trying to adopt effective pre-icing protocols. No significant difference in the functional agility times between the control group and treatment group following a 20-minute ice pack application to the lateral uninjured ankle was hypothesized for this current study. The alpha was pre-set at $\mathrm{p}>0.05$. to determine if there was any treatment effect. This chapter presents the statistical results obtained from testing the control and treatment, male and female, subjects' performance level on functional agility. The mean difference in pre to posttest times for 
the Shuttle Run, Carioca Maneuver and Figure eight is described along with an analysis of statistical findings comparing the results of treatment versus control groups' scores. This chapter concludes by describing typical verbal responses given by the male and female treatment subjects tested.

\section{Subjects/Testing Results}

Twenty-two college-aged subjects (females $=12$, males $=10$ ) from West Valley College, Saratoga, California, met the healthy subject criteria, and participated in two days of testing (pretest, posttest) as treatment or control group subjects. The 12 female soccer players and 10 male football players volunteered as subjects. The male and female subjects were tested on separate days, and time between the pretest and posttest was less than one week.

Table 1 presents the descriptive and demographic information for the 22 subjects. An independent t-test was conducted on the overall mean change from pretest to posttest agility times (Shuttle Run, Carioca Maneuver, and Figure Eight) for both male and female, treatment versus control, subjects. The alpha level for each of the six independent $t$-tests ( 3 male, 3 female) was preset at 0.05 . Because six $\mathrm{t}$-tests were administered overall, a Bonferroni Adjustment Technique was applied to adjust an otherwise inflated alpha level $(.05 / 6=.008)$ The adjusted alpha level was .008 . Mean and standard deviations for the three functional agility mean scores are listed in Table 2 (Female Subjects) and Table 3 (Male Subjects). 
Table 1

Descriptive Data for Subjects

\begin{tabular}{cccllll}
\hline ID\# & Test Leg & treat/control & sport & position & yrs exp. & eligibility yr \\
\hline 1 & left & tx & Soccer sweeper & 6 & 1 \\
2 & right & C & Soccer defense & 12 & 2 \\
3 & left & C & Soccer sweeper & 12 & 1 \\
4 & right & C & Soccer midfielder & 10 & 1 \\
5 & right & C & Soccer goalie & 1 & 1 \\
6 & right & tx & Soccer halfback & 7 & 2 \\
7 & right & tx & Soccer rt. middle & 3 & 3 \\
8 & left & tx & Soccer striker & 8 & 2 \\
9 & right & tx & Soccer forward & 5 & 2 \\
10 & left & C & Soccer sweeper & 3 & 1 \\
11 & left & tx & Soccer defense & 4 & 1 \\
12 & right & C & Soccer forward & 7 & 2 \\
13 & right & C & Football receiver & 0 & 1 \\
14 & right & C & Football def. back & 5 & 2 \\
15 & right & tx & Football linebacker & 1 & 2 \\
16 & left & C & Football receiver & 1 & 1 \\
17 & right & tx & Football runback & 1 & 1 \\
18 & left & tx & Football receiver & 0 & 1 \\
19 & left & tx & Football tight-end & 1 & 2 \\
20 & right & C & Football def. back & 2 & 2 \\
21 & left & tx & Football def. back & 6 & 2 \\
\hline & left & C & Football qtr. back & 1 & 2 \\
\hline & & & & & 2 & 2 \\
\hline
\end{tabular}




\section{Table 2}

Agility Scores for Female Subjects (Mean + SD)

\begin{tabular}{lcccccc}
\hline & \multicolumn{2}{c}{ Treatment } & & \multicolumn{2}{c}{ Control } \\
\cline { 2 - 3 } \cline { 6 - 6 } & Pretest & Posttest & & Pretest & Posttest \\
Shuttle Run & $8.23(.55)$ & $8.42(.39)$ & & $8.40(.28)$ & $8.47(.34)$ \\
Carioca Maneuver & $7.81(.52)$ & $7.68(.63)$ & & $8.17(.56)$ & $7.83(.55)$ \\
Figure Eight & $11.83(.38)$ & $11.82(.19)$ & & $11.85(.30)$ & $11.79(.47)$ \\
\hline
\end{tabular}

Table 3

Agility Scores for Male Subjects (Mean + SD)

\begin{tabular}{lccccc}
\hline & \multicolumn{2}{c}{ Treatment } & & \multicolumn{2}{c}{ Control } \\
\cline { 2 - 3 } \cline { 5 - 6 } \cline { 5 - 6 } & Pretest & Posttest & & Pretest & Posttest \\
Shuttle Run & $7.47(.30)$ & $7.54(.27)$ & & $7.23(.59)$ & $7.24(.40)$ \\
Carioca Maneuver & $6.54(.50)$ & $6.65(.54)$ & & $6.57(.68)$ & $6.35(.47)$ \\
Figure Eight & $10.48(.37)$ & $10.68(.44)$ & & $10.04(.85)$ & $10.05(.58)$ \\
\hline
\end{tabular}

Results of the $\mathrm{t}$-test on the female subjects' overall mean change Shuttle Run indicated there was no significant difference $(\mathrm{p}>.008)$ between the treatment and control group mean difference in Shuttle Run times $[t(2,10)=0.58, P=0.57]$. See Table 4 for the overall mean change in female subjects' pretest - posttest agility scores. Three of the six female treatment 
subjects, for the Carioca maneuver, had improved agility times $(0.36,0.70$, and 1.28 seconds), but the difference was not statistically significant $(p>.008)$ when the overall mean change was compared to the control group $[t(2,10)=0.46, P$ $=0.65 \mathrm{l}$. This was also the case with results from the Figure Eight test in which four of the six treatment subjects had improved posttest agility times $(0.07,0.17,0.19$ and 0.21 seconds), but results were not statistically significant $[\mathrm{t}(2,10)=0.33, \mathrm{P}=0.75]$.

\section{Table 4}

Mean Differences for Female Subjects' Pretest-Posttest Change in Scores

\begin{tabular}{lccc}
\hline & Treatment & Control \\
\cline { 2 - 3 } Shuttle Run & -0.19 & -0.72 \\
Carioca Maneuver & 0.13 & 0.35 \\
Figure Eight & 0.01 & 0.06 \\
\hline
\end{tabular}

There was no significant difference $(p>.008)$ between male, treatment versus control, agility times for the Shuttle $\operatorname{Run}[\mathrm{t}(2,8)=0.35, P=0.74]$, and the mean difference in agility times was 0.14 seconds. See Table 5 for the overall mean change in male subjects' pretest - posttest agility scores. The male subjects' pretest and posttest results for the Carioca Maneuver indicated no significant difference $(\mathrm{p}>.008)$ in overall mean change between the treatment and control subjects $[\mathrm{t}(2,8)=1.75, \mathrm{P}=0.15]$, and similar results 
Table 5

Mean Differences for Male Subjects' Pretest -Posttest Change in Scores

Shuttle Run

Carioca Maneuver

Figure Eight
Treatment

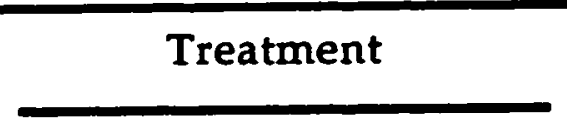

$-0.07$

$-0.11$

$-0.21$
Control

$-0.01$

0.22

$-0.01$

were obtained when comparing the overall mean change in pretest and posttest Figure Eight agility times $[t(2,8=0.90, P=0.39]$. Thirty-nine percent of the posttest scores revealed improved functional agility times for treatment subjects following ice pack application. This study's statistical analyses (independent $\mathbf{t}$-tests) for the male and female subjects revealed there were no significant differences $(p>.008)$ in the overall mean change for scores between treatment versus control groups.

\section{Subjective Responses}

During the second testing day, all treatment subjects had a 20-minute ice pack application to the lateral ankle. They were instructed to jog 50 yards to the first agility test station, immediately following the removal of the ice pack, and instructed to perform a 15-second calf stretch. At the first testing station only, all treatment subjects were asked to verbally describe how it felt running and cutting on the pre-iced ankle. Evans et al. (1995) recorded 
subjective responses from treatment subjects in their study to identify any psychological apprehension due to the effects of cold. Findings from the subjective responses in this study were informative, and conveyed how treatment subjects felt during testing. Twelve subjects verbally reported tingling and numbness in lateral ankle and foot, two reported the ankle felt cold and had discomfort, and one reported the ankle felt warm and tingling. Three subjects complained of difficulty cutting during the agility drills, and the remaining subjects stated they felt comfortable performing the agility drills. 


\section{Chapter V}

\section{SUMMARY, DISCUSSION, CONCLUSIONS, AND RECOMMENDATIONS}

\section{Introduction}

Cryotherapy is currently one of the most common therapeutic modalities utilized by athletic trainers to treat injuries (Merrick et al., 1993), yet the available literature in the sports medicine field has conveyed conflicting recommendations regarding the practice of pre-icing prior to participating in sports activity or therapeutic exercise (Cross et al., 1996; Evans et al., 1995; Knight et al., 1997; Thieme et al., 1996). The available literature regarding the effects of pre-icing has primarily been laboratory studies investigating cryotherapy's effect on muscle strength (Barnes \& Larson, 1985; Coppin et al., 1978), balance testing using laboratory equipment (Gandevia \& McCloskey, 1976; Glencross \& Thorton, 1981), joint movement replication studies (Garn \& Newton, 1988; Gross, 1987), and the effects of ice water immersion on muscle (Coppin et al., 1978) and joints (Evans et al., 1995; Thieme et al., 1996). Two recent studies (Evans et al., 1995; Cross et al., 1996) are credited with investigating the effects of pre-icing (ice water immersion) on functional agility tests. Although these research studies were both conducted in a laboratory, the results provided athletic trainers with valuable information regarding the effects of pre-icing on functional agility. Results from the two similar cryotherapy studies however, yielded conflicting findings and recommendations for pre-icing. 
Athletic trainers and other health care professionals could benefit from more studies like Evans et al. and Cross et al. to establish effective pre-icing protocols for injured athletes.

\section{Summary}

The purpose of this study was to determine how three functional agility tests were affected by a 20 -minute ice pack application to the lateral non-injured ankle. Twenty-two male football $(n=10)$ and female soccer athletes ( $n=12)$ served as the treatment or control groups, and were tested on a grass field wearing turf shoes. The outdoor setting was designed to simulate the sidelines of a game field in which athletic trainers administered cryotherapy (ice and compression wraps) to treat injuries. A thorough literature review revealed that an outdoor cryotherapy study like this had never been conducted. This study was similar to the laboratory framework of previous studies (Cross et al., 1996; Evans et al., 1995;) by utilizing similar functional agility tests (Shuttle Run, Carioca Maneuver, and Figure Eight), but used ice packs with compression wraps, rather than ice water immersion, to simulate the more common modality used by athletic trainers. The treatment and control groups performed three trials each of the three functional agility tests on two different test days in a pretest and posttest design. No overall mean change between any of the pre and post agility tests, for the treatment and control subjects, following the 20-minute ice pack application were hypothesized. The alpha level was preset at 05 . 
Results from the pretest and posttest mean differences indicated there were no significant differences in the stopwatch times for the male and female subjects, treatment versus control, on any of the functional agility tests.

\section{Discussion}

The 20-minute ice pack application to the male and female treatment subjects did not significantly affect the level of functional agility when tested on natural turf (grass). The mean difference in pretest-posttest stopwatch times for the female treatment subjects' agility times were two tenths of a second slower for the shuttle run, but 0.13 and .06 seconds faster for the carioca maneuver and figure eight, respectively. The female control subjects' also improved for the carioca maneuver (0.34) and figure eight $(0.06)$, but were slower for the shuttle run $(-0.07)$. These differences in treatment versus control mean scores were not statistically significant. There was also no significant difference in the pretest - posttest, treatment versus control, times for the male subjects that participated in this study. There was an overall mean change in pretest - posttest times, as the male subjects were slower by one to two tenths of a second for each of the three agility tests. This, however, was not statistically significant. Agility testing at each of the three stations was randomly counterbalanced for all subjects, and there was no difference in agility times due to agility station order. However, each of the subjects were given only one practice trial followed by three recorded trials. The agility times possibly improved as they became more familiar with the agility drill. Treatment subjects may have become more or less apprehensive on the pre- 
iced ankle after a few trials, and fatigue may have also been a factor as many of the male and female subjects appeared short of breath midway through pre and post testing. The 20-minute ice pack treatment did not affect the female or male subjects' level of functional agility, wearing turf shoes, on the grass field. The results were similar to Evans et al. (1995) in which a 20-minute ice water immersion to the foot and ankle did not adversely affect functional agility. Evans et al. had also tested functional agility using similar agility tests, but tested only male subjects $(n=24)$ on a gymnasium floor (flat-even surface) wearing tennis shoes. In comparing the results (stopwatch times) of the two studies, the uneven grass surface did not significantly slow the agility times for the male and female treatment subjects.

Cross et al. (1996), however, obtained different results when testing the agility for football (male) and soccer (female) collegiate subjects $(n=20)$ following 20-minute ice water immersion to the lower leg. These subjects were also tested indoors on a flat-even surface, and found to have significantly reduced shuttle run and vertical jump scores following cold application. The reduced times may have been caused by the entire lower leg being immersed (calf muscle), rather than the ankle joint alone. Prior studies on the effects of cryotherapy on muscle tissue (Barnes \& Larson, 1985; Coppin et al., 1978) had found muscle strength and function to be impaired with preicing. Evans et al. (1995) advocated pre-icing before exercise without concern for an athlete's agility being altered, while Cross et al. (1996) conveyed the potential risk of impaired performance and possible injury. While the pre- 
iced calf muscle may have impaired the function of subjects in one study (Cross et al.), Evans et al. found that icing the ankle alone did not affect the sensory receptors responsible for proprioception. The subjects' ankles in this study may not have reached the same low temperatures as the two previous studies (Cross et al., 1996; Evans et al., 1995) to significantly impair agility or cause apprehension. Both studies used ice water immersion and cooled a greater surface area, while the ice pack was applied to the lateral ankle with a elastic compression wrap. Some advantages to the ice pack application were that the elastic compression and leg elevation simulated the protocol more often used by athletic trainers for treating acute injuries. Cooling temperature was not measured in this study, but the literature regarding ice pack cooling temperatures provided important data supporting its effectiveness as a cold modality.

Merrick et al. (1993) found ice pack and compression to be very effective at lowering soft-tissue temperatures. Twenty-minute post-application temperatures were measured and still had not regained pre-application temperatures.

Taber et al. (1992) found a cold gel pack, applied to the lateral ankle for 20-minutes, to be effective at lowering ankle temperatures. Mancuso and Knight (1992) investigated the effects of prior exercise on the rate of cooling (30-minute ice pack) the lateral ankle, and found that it did not affect the rate of cooling. The subjective responses for this current study indicated treatment subjects experienced tingling, numbness, cold and aching 
sensations around the ankle during agility testing. Many of these symptoms have been identified by Starkey (1976) as typical symptoms experienced from the analgesic effect of cold therapy. The pre-icing protocol in this study was assumed to be just as effective as the above mentioned studies at attaining analgesia in the ankle of all treatment subjects tested. In one prior study (Cross et al., 1996), the researchers observed obvious balance deficits during pre-iced agility testing, while another study (Evans et al., 1995) did not find the analgesic effect of pre-icing to affect balance during agility testing. While testing pre-iced subjects for this current study, there were a few slips with cutting. Two female treatment subjects slipped when cutting around the figure eight cone, while one female control subject slipped during the shuttle run. One male treatment and two control subjects slipped while attempting to turn around figure eight cones. One male treatment subject slipped during the shuttle run. This appeared to occur as some subjects tried to quickly accelerate following quick deceleration. The turf was dry and one-inch in length, but the turf shoes appeared to dig up and tear the grass at points where cutting to change direction. There were, however, no falls or injuries during testing. There was less control for external factors in this study due to testing the subjects out on the field, rather than in the laboratory. Possibly, running on grass (uneven surface) wearing turf shoes required more ankle proprioception for cutting and maneuvering during the agility drills than the prior laboratory studies (Cross et al., 1996; Evans et al., 1995) on flat surfaces. 
This was the first field study that examined functional agility on a grass field following cryotherapy, and the results conveyed that pre-icing did not affect the level of functional agility in soccer and football athletes.

\section{Practical Application}

Currently, there are no pre-icing protocols for certified athletic trainers to follow for treating athletes prior to competition or therapeutic exercise. In some cases it could be assumed that athletic trainers reviewed the literature, primarily laboratory studies, and developed their own protocols based on experimenting and adopting methods from these prior studies. This study examined how pre-icing affected functional agility on a grass field wearing turf shoes. There was less external control, compared to laboratory testing, but outdoor field testing more effectively simulated the environment and playing surface in which most athletes compete. In determining whether an athlete is appropriate for return to play following cryotherapy for an mild ankle sprain, athletic trainers need to know the effects it may have on the athlete's level of functional agility. Athletes need to be tested on the same type of playing surface, under similar environmental conditions, to effectively determine whether performance will be impaired. This outdoor field study simulated those realistic conditions for athletic trainers assessing and treating injuries in the field. Pre-icing an ankle does not significantly affect an athlete's level of functional agility when tested on natural turf. It is, however, recommended that athletic trainers assess the severity and psychological effects of the injury to avoid impaired performance or re-injury. 


\section{Conclusions}

The following conclusions were established based on the results.

1. There was no significant overall mean change in pretest - posttest shuttle run, functional agility, times for the treatment versus control male football subjects.

2. There was no significant overall mean change in pretest - posttest carioca maneuver, functional agility, times for the treatment versus control male football subjects.

3. There was no significant overall mean change in pretest - posttest figure eight, functional agility, times for the treatment versus control male football subjects.

4. There was no significant overall mean change in pretest - posttest shuttle run, functional agility, times for the treatment versus control female soccer subjects.

5. There was no significant overall mean change in pretest - posttest carioca maneuver, functional agility, times for the treatment versus control female soccer subjects.

6. There was no significant overall mean change in pretest - posttest figure eight, functional agility, times for the treatment versus control female soccer subjects.

7. Subjective responses indicated all treatment subjects experienced analgesia in the lateral non-injured ankle prior to agility testing, but had no obvious loss of balance or pain during the testing. 


\section{Recommendations}

The following recommendations were made for future investigations.

1. Cold application, prior to performance, can be used on joint tissue without significantly altering agility.

2. A 20-minute ice pack application to the lateral non-injured ankle is effective at producing analgesia.

3. A 20-minute ice pack application to the lateral non-injured ankle did not appear to cause obvious loss of balance, pain or psychological apprehension during functional agility testing.

\section{Future Studies}

1. Future studies should measure or monitor skin temperatures during pre-icing and following functional agility testing.

2. Future studies should test a greater number of subjects from a greater variety of sports.

3. Future studies should compare injured versus non-injured subjects.

4. Future studies should standardize the time of day for subjects to be tested outdoors.

5. A questionnaire should be issued to subjects after testing to obtain more subjective data on the effects of icing. 


\section{References}

Baker, R. J., \& Bell, G. W. (1991). The effect of therapeutic modalities on blood flow in the human calf. Lournal of Orthopaedic \& Sports Physical Therapy. 13 (1), 23-27.

Barnes, W. S., \& Larson, M. R. (1985). Effects of localized hyper- and hypothermia on maximal isometric grip strength. American Journal of Physical Medicine, 64 (6), 305-313.

Barrack, R. L., Skinner, H. B., Brunet, M. E., \& Haddad, R. J. (1983).

Functional performance of the knee after intra-articular anesthesia. American Lournal of Sports Medicine, 11 (4), 258-261.

Birmingham, T. B., Chesworth, B. M., Hartsell, H. D., Stevenson, A. L., Lapenskie, G. L., \& Vandervoort, A. A. (1997). Peak passive resistive torque at maximum inversion range of motion in subjects with recurrent ankle inversion sprains. Lournal of Orthopaedic \& Sports Physical Therapy, 25 (5), $342-348$.

Bocobo, C., Fast, A., Kingery, W., \& Kaplan, M. (1991). The effects of ice on intra-articular temperature in the knee of the dog. American Journal of Physical Medicine \& Rehabilitation, 70 (4), 181-185.

Bolgla, L. A., \& Keskula, D. R. (1997). Reliability of lower extremity functional performance tests. Lournal of Orthopaedic \& Sports Physical Therapy, 26 (3), 138-142. 
Borsa, P. A., Lephart, S. M., Irrgang, J. J., Safran, M. R., \& Fu, F. (1997). The effects of joint position and direction of joint motion on proprioceptive sensibility in anterior cruciate ligament-deficient athletes. American Journal of Sports Medicine, 25 (3), 336-340.

Brooks, K. A., Ingersoll, C. D., \& Knight, K. L. (1995). Force perception at the ankle following heat and cold applications. Lournal of Athletic Training, 30 (2), S-35.

Bugaj, R. (1975). The cooling, analgesic, and rewarming effects of ice massage on localized skin. Physical Therapy, 55 (1), 11-18.

Coppin, E. G., Livingstone, S. D., \& Kuehn, L. A. (1978). Effects on handgrip strength due to arm immersion in a 10 degree Celsius water bath. Aviation, Space, and Environmental Medicine, 49 (11), 1322-1326.

Cornwall, M. W. (1994). Effect of temperature on muscle force and rate of muscle force production in men and women. Iournal of Orthopaedic \& Sports Physical Therapy, 20 (2), 74-79.

Cross, K. M., Wilson, R. W., \& Perrin, D. H. (1996). Functional performance following an ice immersion to the lower extremity. Lournal of Athletic Training, 31 (2), 113-116.

De Carlo, M. S., Rettig, J., \& Talbot, R. W. (1986). Evaluation of ankle joint proprioception following injection of the anterior talofibular ligament. Lournal of Orthopaedic \& Sports Physical Therapy, 8 (2), 70-76. 
Dvir, Z., Koren, E., \& Halperin, N. (1988). Knee joint position sense following reconstruction of the anterior cruciate ligament. Lournal of Orthopaedic \& Sports Physical Therapy. 10 (4), 117-120.

Evans, T. A., Ingersoll, C., Knight, K. L., \& Worrel, T. (1995). Agility following the application of cold therapy. Lournal of Athletic Training, 30 (3), 231-234.

Fandel, D. M. (1994). The athletic trainer and the training room. In Mellion, M. B. (Eds.) Sports Medicine Secrets (pp. 4-6) St. Louis, MO: Mosby Company.

Forkin, D. M., Koczur, C., Battle, R., \& Newton, R. A. (1996). Evaluation of kinesthetic deficits indicative of balance control in gymnasts with unilateral chronic ankle sprains. Lournal of Orthopaedic \& Sports Physical Therapy, 23 (4), 245-250.

Gandevia, S. C., \& McCloskey, D. I. (1976). Joint sense, muscle sense, and their combination as position sense, measured at the distal interphalangeal joint of the middle finger. Lournal of Physiology, 260, 387-407.

Garn, S. N., \& Newton, R. A. (1988). Kinesthetic awareness in subjects with multiple ankle sprains. Physical Therapy, 68 (11), 1667-1671.

Glencross, D., \& Thornton, E. (1981). Position sense following joint injury. Journal of Sports Medicine, 21, 23-27.

Grigg, P. (1994). Peripheral neural mechanisms in propriocepton. Lournal of Sport Rehabilitation, 3, 2-17. 
Gross, M. T. (1987). Effects of recurrent lateral ankle sprains on active and passive judgments of joint position. Physical Therapy, 67 (10), 1505-1509.

Guido, J., Voight, M. L., Blackburn, T. A., Kidder, J. D., \& Nord, S. (1997). The effects of chronic effusion on knee joint proprioception: A case study. Iournal of Orthopaedic \& Sports Physical Therapy, 25 (3), 208-212.

Hocutt, J. E., Jaffe, R., Rylander, C. R., \& Beebe, J. K. (1982). Cryotherapy in ankle sprains. American Journal of Sports Medicine, 10 (3), 316-319.

Howard, R. L. Kraemer, W. J., Stanley, D. C. Armstrong, L. E., \& Maresh, C. M. (1994). The effects of cold immersion on muscle strength. Lournal of Strength and Conditioning, 8 (3), 129-133.

Ingersoll, C. D., Knight, K. L., \& Merrick, M. A. (1992). Sensory perception of the foot and ankle following therapeutic applications of heat and cold. Lournal of Athletic Training 27 (3), 231-233.

Keskula, D. R., Duncan, J. B., Davis, V. L., \& Finley, P. W. (1996). Functional outcome measures for knee dysfunction assessment. Lournal of Athletic Training, 31 (2), 105-110.

Knight, K. L., \& Londeree, B. R. (1979). Comparison of blood flow in the ankle of uninjured subjects during therapeutic applications of heat, cold, and exercise. Medicine and Science in Sports and Exercise, 12 (1), 76-79.

Knight, K. L., Okuda, I., Ingersoll, C. D., \& Edwards, J. E. (1997). The effects of cold application on nerve conduction velocity and muscle force. Lournal of Athletic Training, 32 (2), S-5. Abstract 
Konradsen, L., Voight, M., \& Hojsgaard, C. (1997). Ankle inversion injuries: The role of the dynamic defense mechanism. American Journal of Sports Medicine 25 (1), 54-58.

Kowal, M. A. (1983). Review of physiological effects of cryotherapy. Iournal of Orthopaedic \& Sports Physical Therapy, 5 (2), 66-73.

LaRiviere, J. A. (1994). The effect of ice immersion on joint position sense. Lournal of Sports Rehabilitation, 3, 58-67.

Lentell, G., Baas, B., Lopez, D., McGuire, L., Sarrels, M., \& Snyder, P. (1995). The contributions of proprioceptive deficits, muscle function, and anatomic laxity to functional instability of the ankle. Journal of Orthopaedic \& Sports Physical Therapy, 21 (4), 206-215.

Lentell, G. L., Katzman, L. L., \& Walters, M. R. (1990). The relationship between muscle function and ankle stability. Lournal of Orthopaedic \& Sports Physical Therapy, 11 (12), 605-611.

Lephart, S. M., Pincivero, D. M., Giraldo, J. L., \& Fu, F. H. (1997). The role of proprioception in the management and rehabilitation of athletic injuries. American Journal of Sports Medicine, 25 (1), 130-137.

Lessard, L. A., Scudds, R. A., Amendola, A., \& Vaz, M. D. (1997). The efficacy of cryotherapy following arthroscopic knee surgery. Lournal of Orthopaedic \& Sports Physical Therapy, 26 (1), 14-22. 
Mancuso, D. L., \& Knight, K. L. (1992). Effects of prior physical activity on skin surface temperature response of the ankle during and after a 30minute ice pack application. Lournal of Athletic Training, 27 (3), 242-248.

McLean, D. A. (1989). The use of cold and superficial heat in the treatment of soft tissue injuries. British Journal of Sports Medicine, 23 (1), 5354.

Meeusen, R. \& Lievens, P. (1986). The use of cryotherapy in sports injuries. Sports Medicine, 3 , 398-414.

Merrick, M. A., Knight, K. L., Ingersoll, C. D., \& Potteiger, J. A. (1993). The effects of ice and compression wraps on intramuscular temperatures at various depths. Iournal of Athletic Training, 28 (3), 236-244.

Narodowy, A., Mahar, L., Donatello, M. C., Knight, K. L., Ingersoll, C. D., \& Kuhlman, J. S. (1996). Cooling the ankle, peroneals or both and the effects on reaction time and movement time. Lournal of Athletic Training 31 , S-52. Abstract.

Newton, R. A. (1982.). Joint receptor contributions to reflexive and kinesthetic responses. Physical Therapy, 62 (1), 22-29.

Palmer, J. E., \& Knight, K. L. (1996). Ankle and thigh skin surface temperature changes with repeated ice pack application. Iournal of Athletic Training, 31 (4), 319-323.

Rowinski, M. J. (1990). Afferent neurobiology of the joint. In Gould, J. A. (Eds.) Orthopaedic and Sports Physical Therapy (pp. 49-61) St. Louis, MO: C.V. Mosby Company. 
Ruiz, D. H., Myrer, J. W., Durrant, E., \& Fellingham, G. W. (1993). Cryotherapy and sequential exercise bouts following cryotherapy on concentric and eccentric strength in the quadriceps. Loumal of Athletic Training 28 (4), 320-324.

Shuler, D. E., Ingersoll, C.D., Knight, K. L., \& Kuhlman, J. S. (1995). Local cold application to the foot and ankle, lower leg, or both effects on a cutting drill. Journal of Athletic Training, 30 S-14. Abstract.

Starkey, J. A. (1976). Treatment of ankle sprains by simultaneous use of intermittent compression and ice packs. American Journal of Sports Medicine, 4 (4), 142-144.

Taber, C., Contryman, K., Fahrenbruch, J., LaCount, K., \& Cornwall, M. W. (1992). Measurement of reactive vasodilation during cold gel pack application to nontraumatized ankles. Physical Therapy, 72 (4), 294-299.

Taylor, B. F., Waring, C. A., \& Brashear, T. A. (1995). The effects of therapeutic application of heat or cold followed by static stretch on hamstring muscle length. Lournal of Orthopaedic \& Sports Physical Therapy, 21 (5), 283286.

Tegner, Y., Lysholm, J., Lysholm, M., \& Gillquist, J. (1986). A performance test to monitor rehabilitation and evaluate anterior cruciate ligament injuries. American Journal of Sports Medicine 14 (2), 156-159.

Thieme, H. A., Ingersoll, C. D., Knight, K. L., \& Ozmun, J. C. (1996). Cooling does not affect knee proprioception. Lournal of Athletic Training, 31 (1), 8-10. 
Weston, M., Taber, C., Casagranda, L., \& Cornwall, M. (1994). Changes in local blood volume during cold gel pack application to traumatized ankles. Lournal of Orthopaedic \& Sports Physical Therapy, 19 (4), 197-199. 
APPENDICES 
Appendix A

Human Subjects Approval Form 
TO:

Paul Starks

17369-B McGuffie Rd.

San José State UNIVERSITY

Orfice of the Academic Viee Proudemt

Aceociots Vles Prosidome

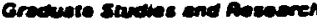

One wasnoton Souve Sin rose Ca 95192.025 voce 4 - 924.2480 iav $=5.324-2477$ E. min osthocsowenoo sesu eav nfto inmun seu cou
Salina, CA 93907

FROM:

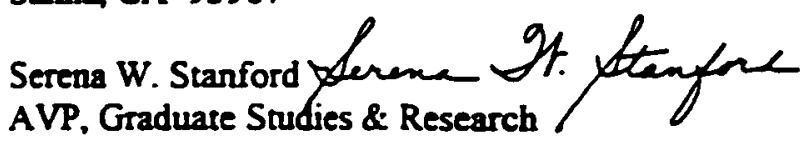

DATE: $\quad$ May 21, 1998

The Human Subjects-Institurional Review Board has approved your request to use human subjects in the study entitled:

"The Effect of Cryotherapy on Three Functional Tests of Agility"

This approval is contingent upon the subjects participating in your research project being appropriately protected from risk. This includes the protection of the anonymity of the subjects' identity when they participate in your research project, and with regard to any and all data that may be collected from the subjects. The Board's approval includes continued monitoring of your research by the Board to assure that the subjects are being adequately and property protected from such risks. If at any time a subject becomes injured or complains of injury, you must notify Serena Stanford, Ph.D., immediately. Injury includes but is not limited to bodily harm, psychological trauma and release of potentially damaging personal information.

Please also be advised that all subjects need to be fully informed and aware that their participation in your research project is voluntary, and that he or she may withdraw from the project at any time. Further, a subject's participation, refusal to participate, or withdrawal will not affect any services the subject is receiving or will receive at the institution in which the research is being conducted.

If you have any questions, please contact me at (408) 924-2480. 
Appendix B

Sign-up Sheet for Volunteer Subjects 


\section{Sign-up Sheet for Volunteer Subjects}

The following list of names below consist of intercollegiate athletes (Football and Soccer) from West Valley College that are interested in being prospective volunteer subjects to participate in a research study.

The researcher for this study will be investigating the effects of cryotherapy on three functional agility tests which will be conducted on two different test days this Summer 1998 at West Valley College, Saratoga, CA.

Football

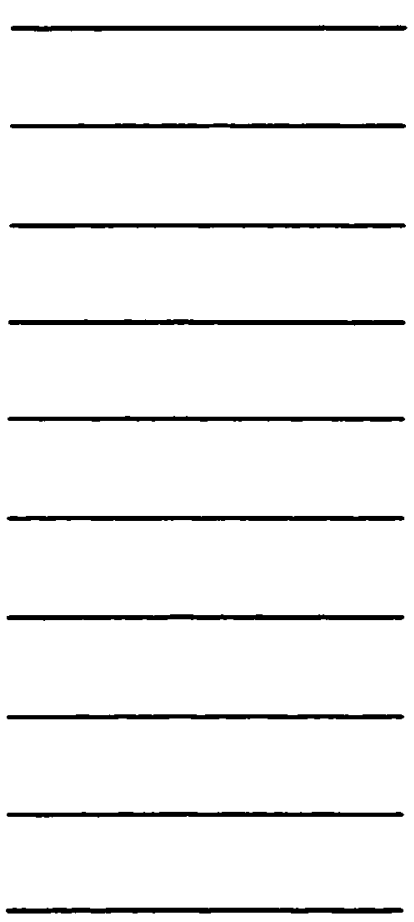

Women's Soccer

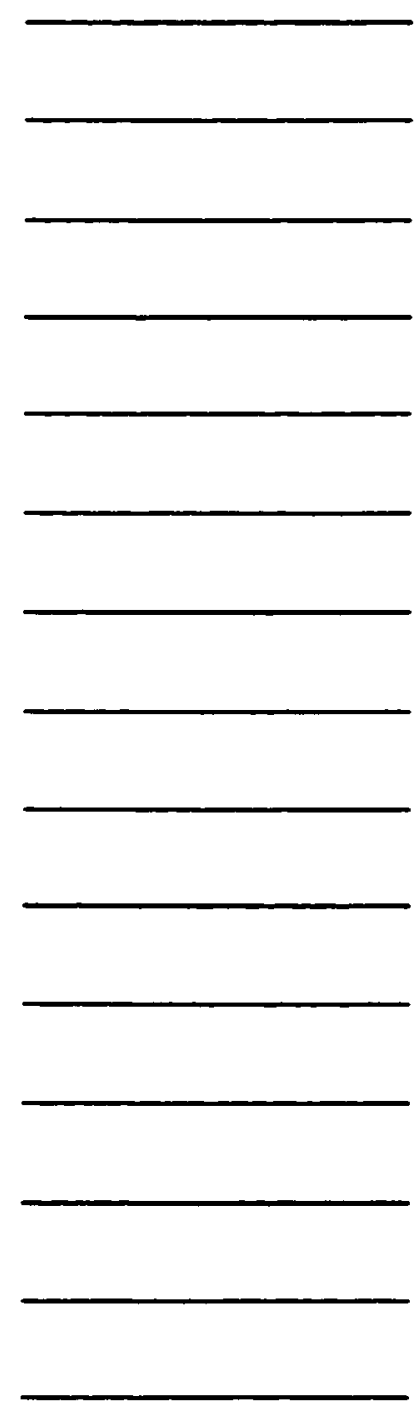

Men's Soccer 
Appendix C

Consent Form 


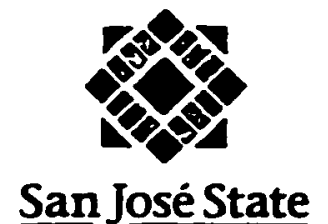

UNIVERSITY

Collece of Aoslied Selences and Ante Dowaroseme of knemen Partermanese

One wannotion soure Sen vose. CA $95192-0054$ voce $408 \cdot 924 \cdot 3010$

$=$ an 400.924 .3053

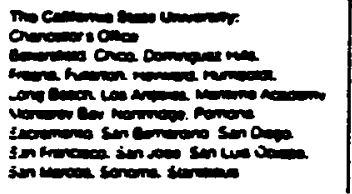

Agreement to Participate in Research

Responsible Investugator:

(Consent Form) Titie of Protocol:

1. I have been asiked to participate in a research study investigating the effects of a 20 minute ice pack application, to the non-domunant ankie, on three functional tests of agility.

2. I will be asked to participate in either a control group ( 3 functional agility tests) or treatment group (ice pack and 3 functional agility tests) on two separate test days in a pre-test/post-test design. The three functional agility tests will simulate typical agility maneuvers performed by athletes in soccer and football.

Testing will take place on the football game field at West Valley College, Saratoga, CA, on May 19th and 21st between 9:00am - 12:00pm.

I will bring cleated shoes and wear shirt and shorts for testung on the grass field.

3. I understand a 20-minute ice pack application to my ankle will cause discomfort and an analgesc (mumbing) effect. I also understand there is a risk for miury performung the three functional agility tests with or without pre-icing the ankle.

4. I will be participating as a volunteer subject for research, and do not expect any discernible benefits.

5. I understand that the results of this study may be published, but no information that could identify me will be inciuded or released.

6. I understand there will be no compensation for participation in this study.

7. Questions regarding this research study may be addressed to Paul Starks (408/6636324). Complaints about this research study may be presented to the Commuce Chair (Greg Payne, P.ED., 408/924-3010). Questions or complaints about research subject's rights, or research-related iriury may be presented to Serena Stanford. PhD. Assocate Academic Vice President for Graduate Studies and Research (408/924-2480).

8. I understand that no service of any kind, to which I am otherwise entitled as a student-athlete at West Valley College, will be lost or jeopardized for choosing not to participate in this study.

9. I voluntarily give consent to participate as a subject for this research study. I understand that I may refuse to participate in this study or in any part of this study. If I decide to participate in this study. I an free to withdrawal at any time without prejudice to my relations with West Valley College or San jose State University.

10. I have received a signed and dated copy of this consent form

- The signature of a mubject on this document indiontes agrecuent to participats in this ctudy.

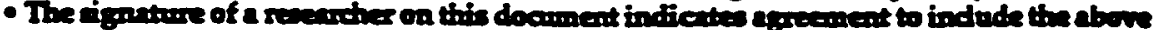

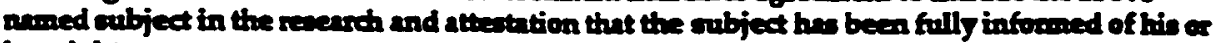
her righte.

Subject's Signature Date

Investigator's Signature Date


Appendix D

Questionnaire for Volunteer Subjects 


\section{Questionnaire for Volunteer Subjects}

Please fill in the blanks.

Intercollegiate Sport:

Playing position:

Years of Experience:

Please circle the appropriate response below:

$$
\text { Gender: male / female }
$$

Yr. of Eligibility: $\quad$ 1st year / 2nd year

1. Have you suffered any type of injury to the lower extremity (from hip to ankle in the past six months? (Yes / No)

2. Do you have any neurovascular disorders in which cold therapy is contraindicated? ( Yes / No)

3. Do you suffer from any equilibrium or balance disorders? (Yes / No)

4. Have you received any cryotherapy treatment to one of your ankles in the past six months? (Yes/No).

5. Are you currently taking any medication that affects your coordination, balance/equilibrium? (Yes / No).

Please feel free to ask for clarification, if any one of the above questions are not clear.

Thank you for taking the time to answer this Questionnaire ! 
Appendix E

Testing Sequence Board 


\section{Appendix $\mathrm{E}$}

Testing Sequence Board

Male Subjects

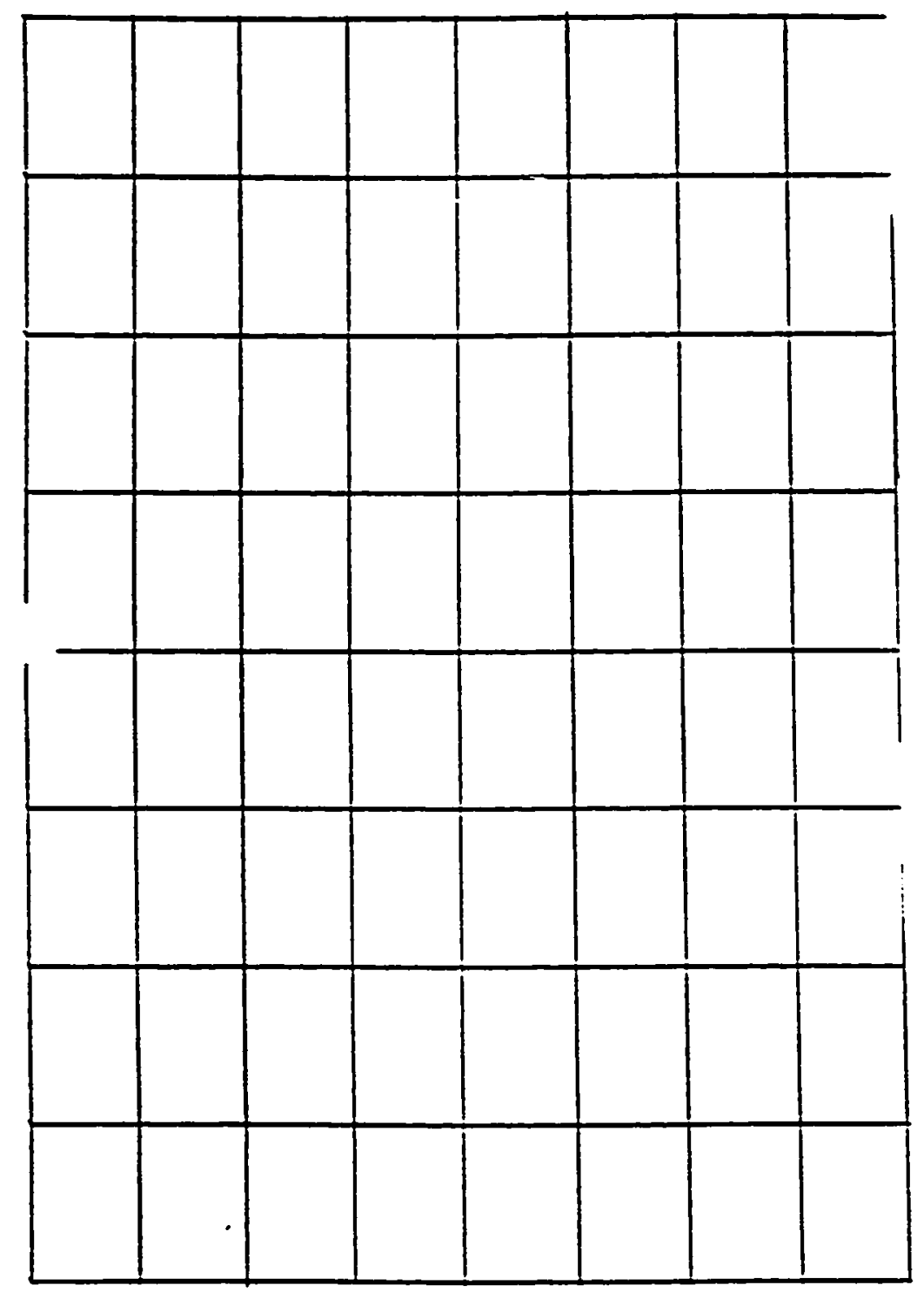

\section{Female Subjects}

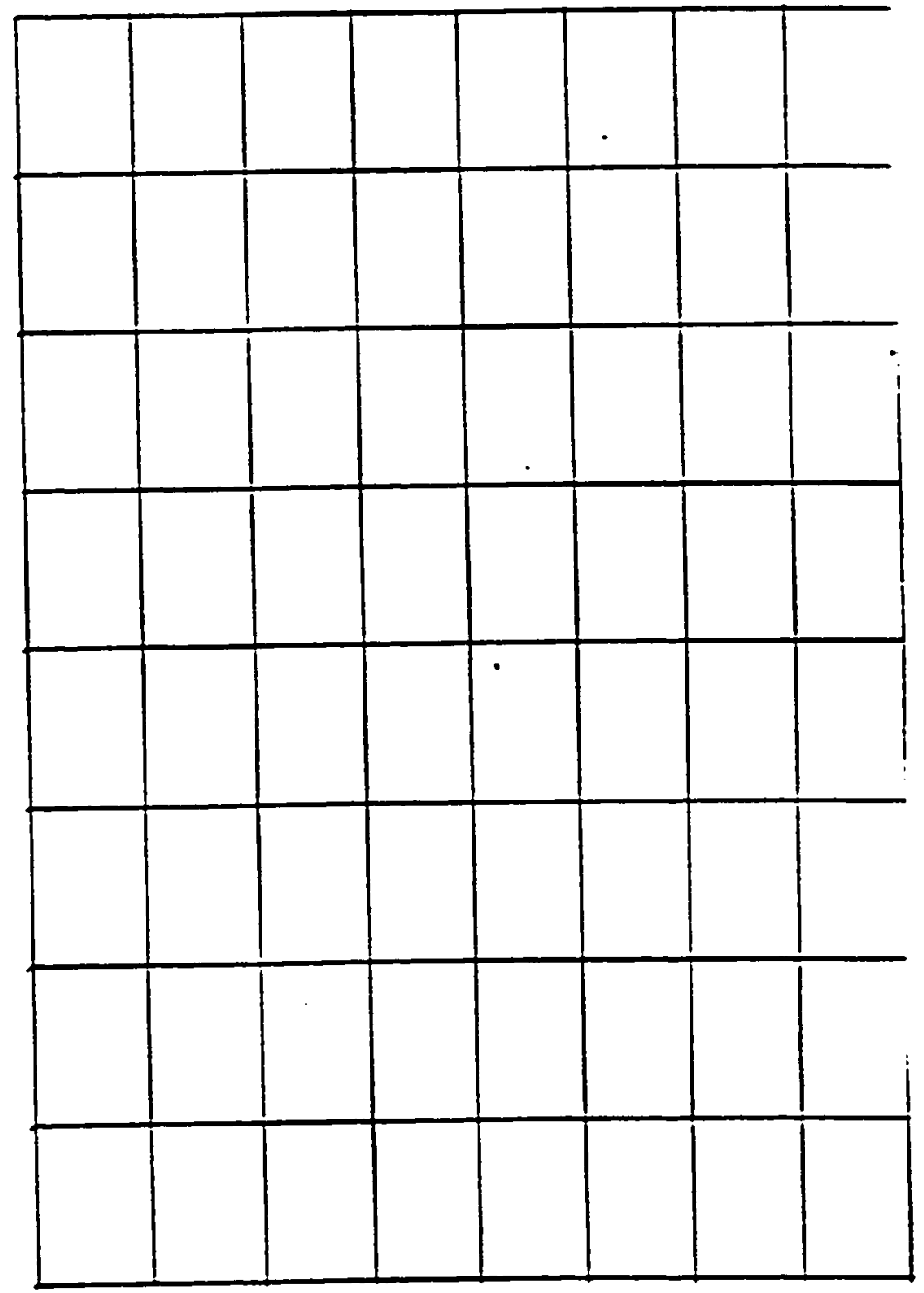


Appendix $\mathrm{F}$

Functional Agility Tests Data Sheet 


\section{Function Agility Tests Data Sheet}

Identification number:

Date / Time: $\perp 198$ am /pm

Location: West Valley College, Saratoga, CA

Examiner's name:

Day 1: Functional Agility Test Times

\begin{tabular}{|c|c|}
\hline$\frac{\text { Shuttle Run }}{\text { (Station 1) }}$ & $\frac{\text { Carioca Drill }}{\text { (Station 2) }}$ \\
\hline
\end{tabular}

Trial 1

Trial 2

Trial 3

Average

Day 2: Functional Agility Test Times (following treatment or control)

$\frac{\text { Shuttle Run }}{\text { (Station 1) }} \quad \frac{\text { Carioca Drill }}{\text { (Station 2) }} \frac{\text { Figure-8 }}{\text { (Station 3) }}$

Trial 1

Trial 2

Trial 3

Average 
Appendix G

Functional Agility Tests 
Functional Agility Tests

Single-Leg Hop for Distance (Keskula et al., 1996; and Tegner et al., 1986)

Purpose: Determined each subject's non-dominant leg for testing.

Instructions: All subjects were wearing cleated shoes and stood with the testing leg's foot just behind a painted line on the grass football field. They were then asked to place hands behind the back and hop horizontally as far as possible, landing on the same testing leg. Arm swinging was permitted. Two practice trials for the left and right lower extremity were performed by each subject, followed by three trials that were measured and recorded. Horizontal distance was measured in centimeters using a tape measure, and the three distance scores were recorded on the Single-Legged Hop Test Data Sheet (Appendix). The average score for left and right lower extremity was compared, and the extremity with the lower average served as the nondominant leg to be treated.

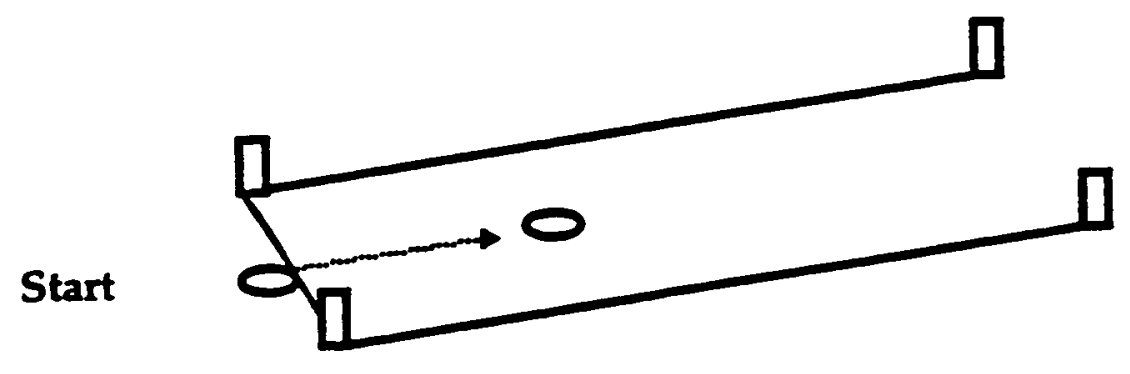

Single-Leg Hop for Distance

Shuttle Run (Cross et al., 1996; Evans et al., 1995 and Keskula et al., 1996)

Purpose: This test reproduced the acceleration and deceleration forces experienced during high-intensity athletics (Evans et al., 1995).

Instructions: All subjects were wearing cleated shoes and performed the shuttle run test on the grass football field. Subjects stood behind a painted line and were asked to sprint forward as fast as possible to another painted line 6.1 meters ahead. Time started when instructed to "go". When approaching the line at 6.1 meters the subjects quickly touched the line with testing leg, and ran back to the starting line twice for a total of 24.4 meters. Time stopped when the subject's foot touched the end line. Three 24.4 meter shuttle runs were timed to the nearest tenth of a second using a stopwatch. The three trial times were then recorded. 


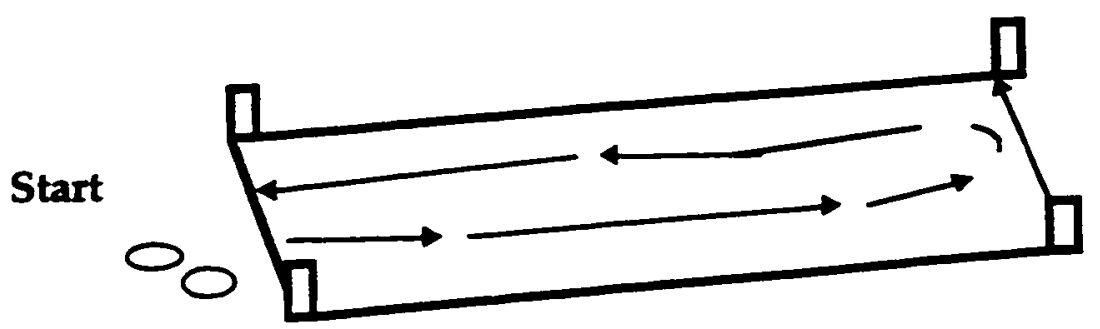

The Shuttle Run

Carioca Test (Evans et al., 1995)

Purpose: The movement for this test demanded maximal ankle eversion with moderate inversion (Evans et al., 1995).

Instructions: All subjects were wearing cleated shoes for this functional agility test. Two painted lines, 12.2 meters apart, served as the testing area for the carioca test. The subjects were instructed to move laterally in a straight line with a shuffle-type maneuver in which the lead leg crossed in front, followed by the trailing leg crossing in front of the leading leg. When a subject was instructed "go", he or she performed this shuffle-type carioca as fast as possible to 12.2 meters, reversed direction and continued as fast as possible back to the start line. Three trials were timed to the nearest tenth of a second using a stopwatch, and then recorded.

Start

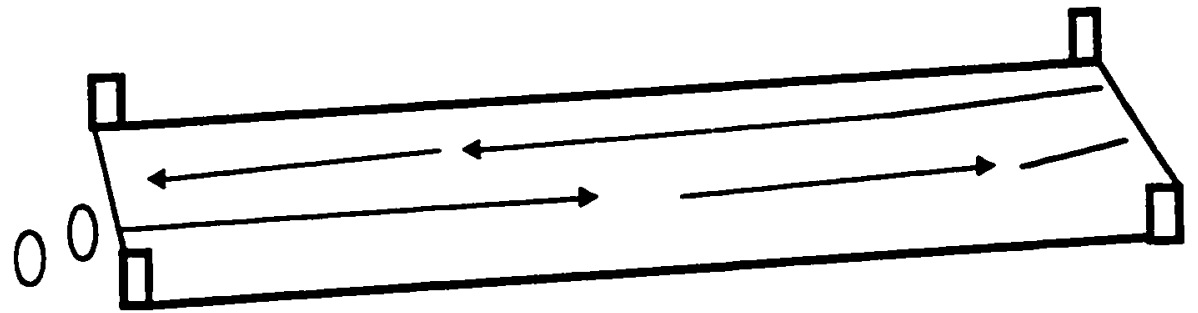

The Carioca 
Figure of Eight Test (Tegner et al., 1986)

Purpose: Simulated the acceleration, deceleration, and pivot-type maneuvers required in sport.

Instructions: All subjects performed this functional agility test wearing cleated shoes. Two fluorescent cones were placed ten meters apart on the grass football field. Subjects were instructed to stand behind the start line to the right of the fluorescent cone. When instructed "go" the stopwatch started and subjects sprinted as fast as possible to the left side of the cone 10 meters away, turning to the right. On return to the start line, the subjects approached the right side of the cone, turning to the lest. This figure of eight maneuver was two laps for a total of a 40 meter test. As each subject crossed the end line at 40 meters, the stopwatch was stopped and the three trial times were recorded.

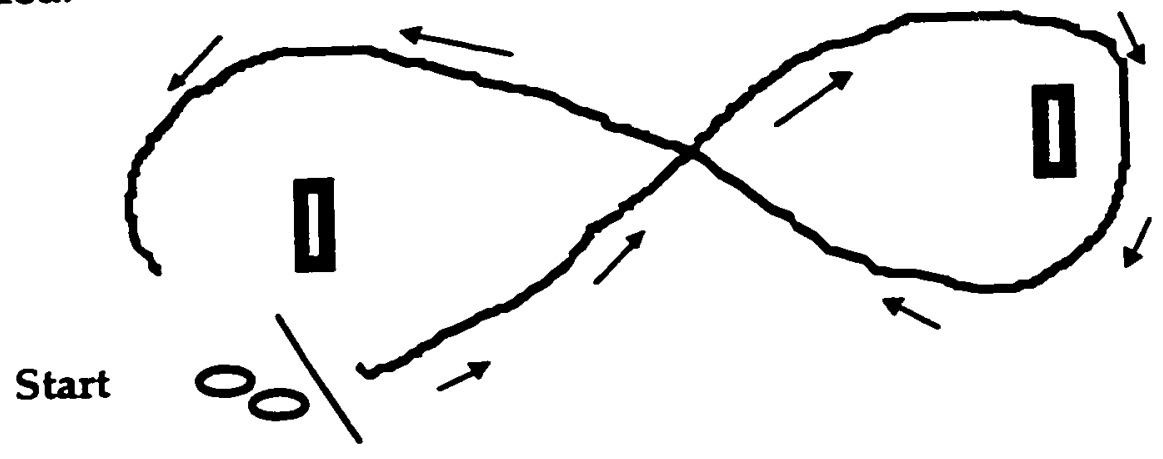

Figure Eight 
Appendix $\mathrm{H}$

Subject Roster Form 


\section{Subject Roster Form}

Subject's Name

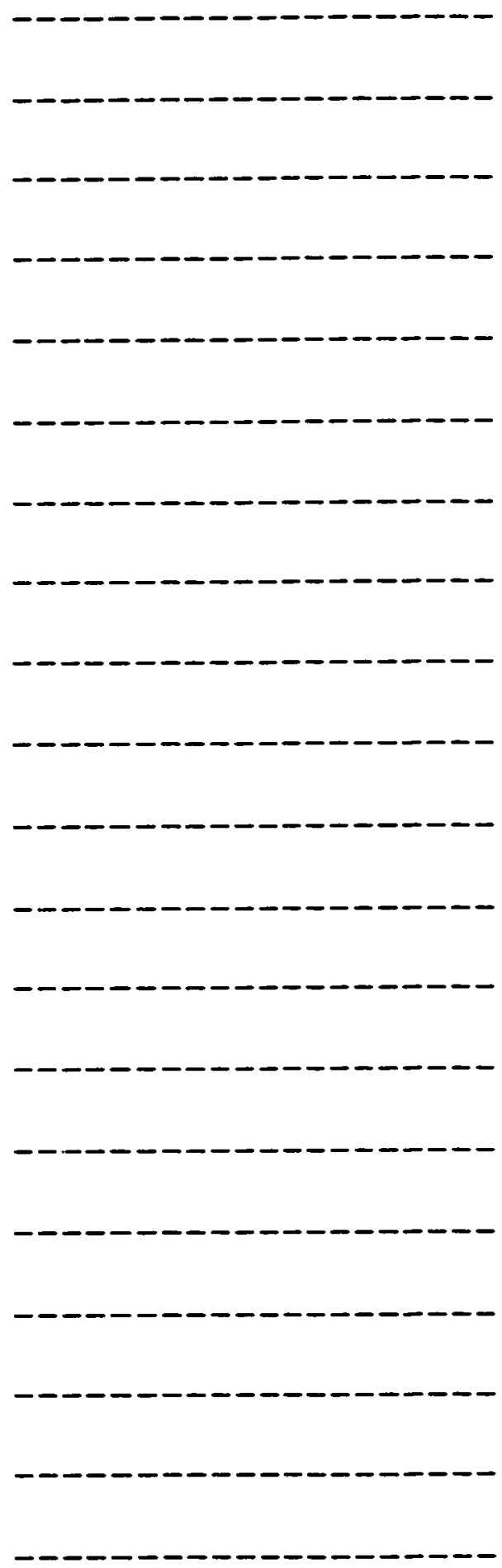

Identification \#

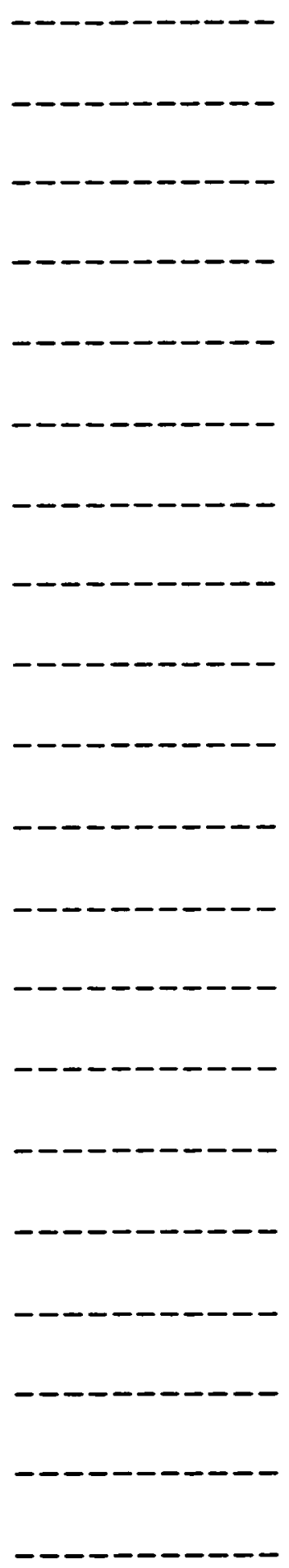


Appendix I

Testing Site 
Testing Site

\author{
West Valley College \\ Football Field \\ Saratoga, California
}

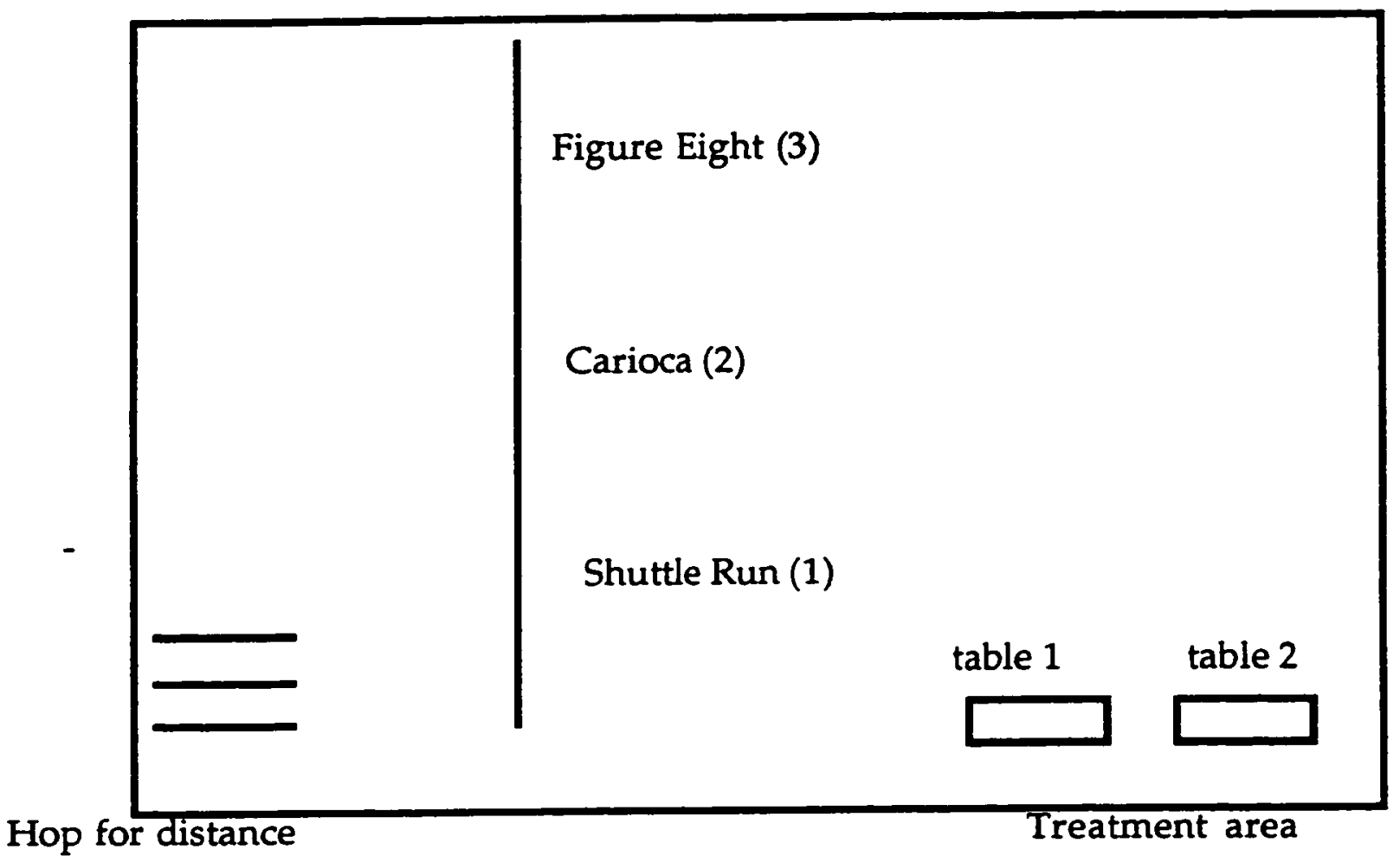

Hop for distance 


\section{IMAGE EVALUATION \\ TEST TARGET (QA-3)}
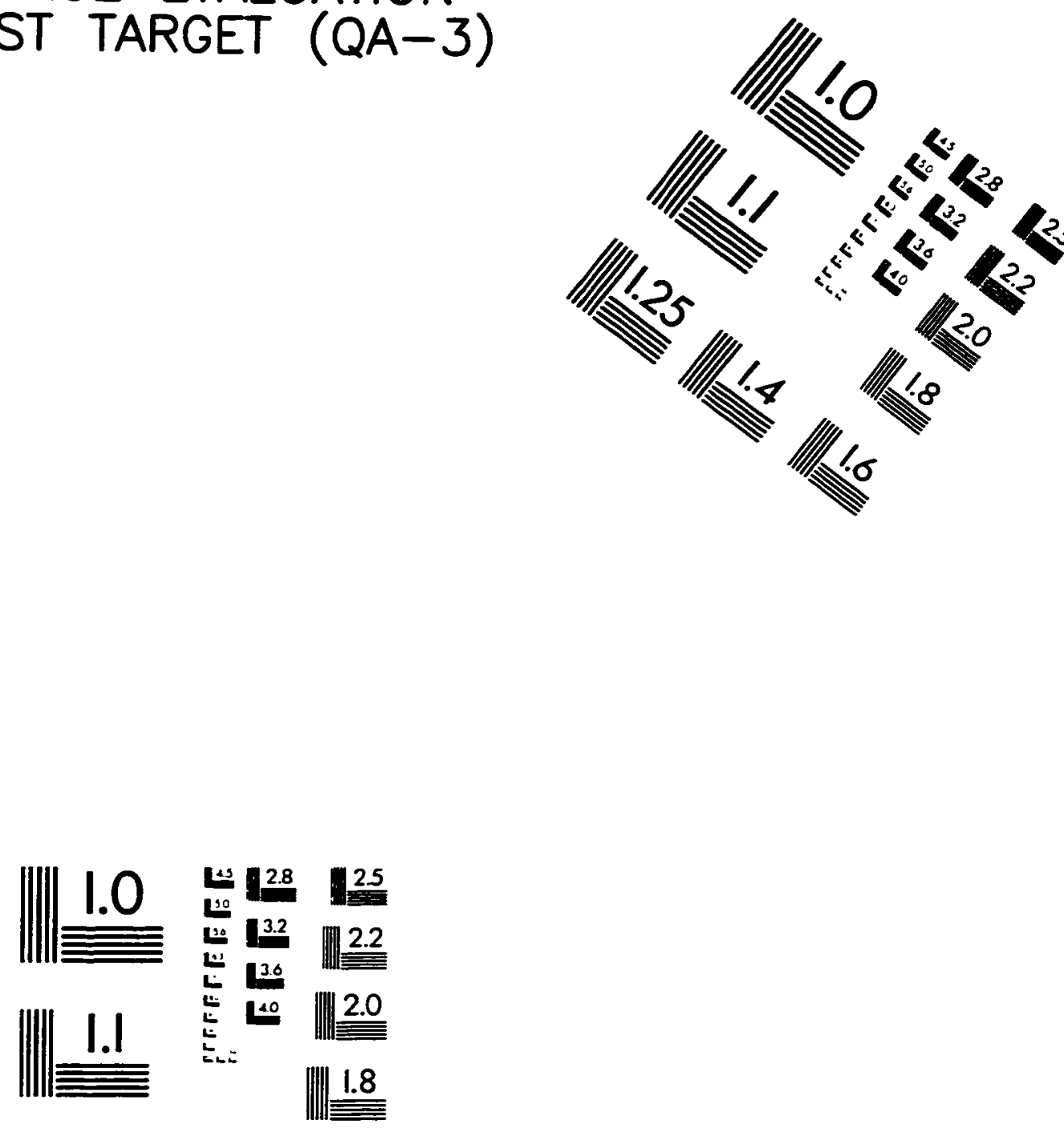

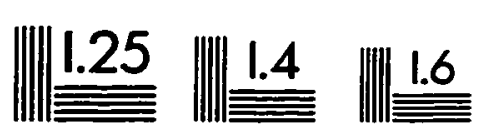
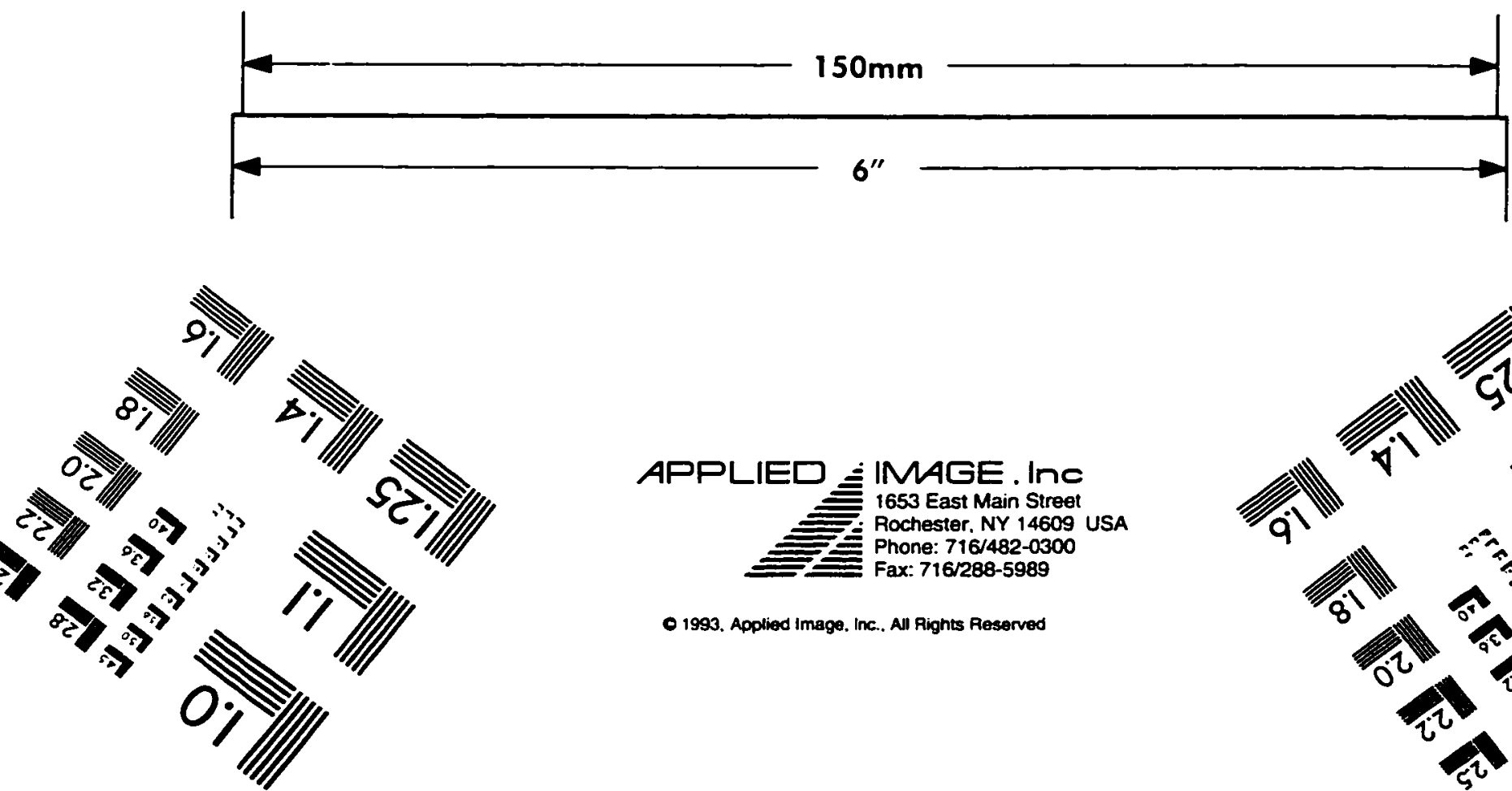

APPLIED ஹIMAGE. InC
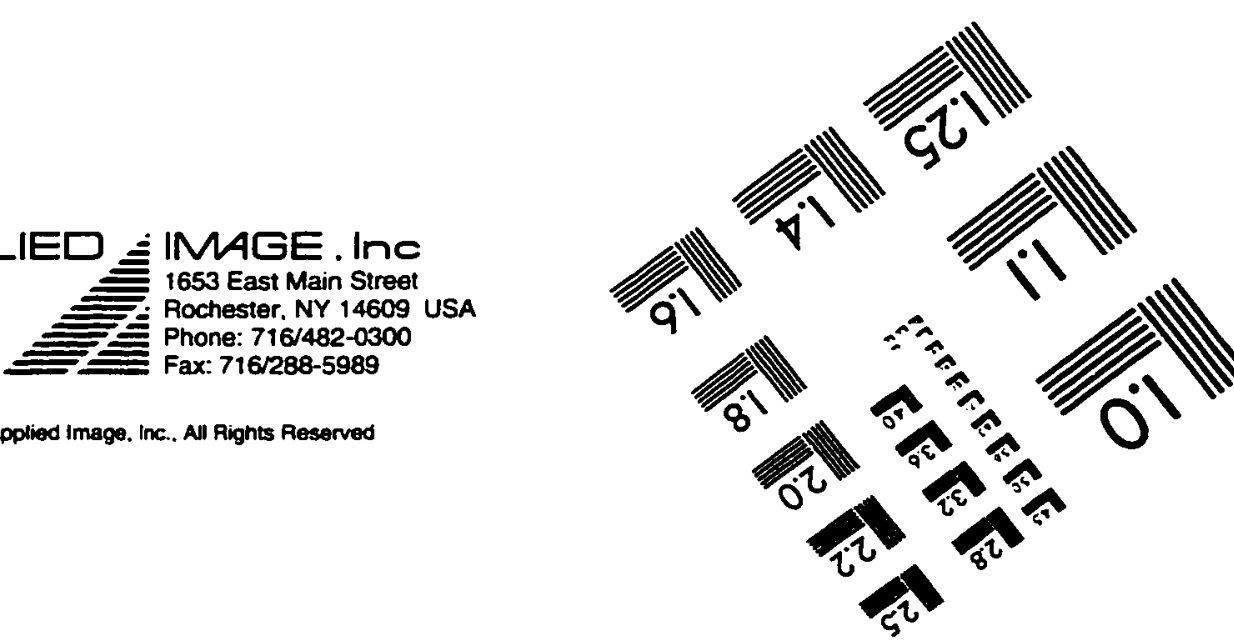